\title{
LA NUPCIALIDAD EN LAS ÁREAS RURALES DE MÉXICO
}

\author{
JULIETA QUILODRÁN \\ El Colegio de México
}

\section{INTRODUCCIÓN}

EN UNA POBLACIÓn que no controla de manera efectiva su fecundidad, la prontitud con la cual se forman las parejas y el tiempo que permanecen unidas, están íntimamente ligadas al número de hijos que cada una de ellas llega a tener. Esto significa que en ausencia de un control deliberado de la fecundidad y, bajo el supuesto de que se mantengan constantes los condicionantes de tipo biológico, los factores de la nupcialidad juegan un papel decisivo sobre los niveles de la fecundidad. Concretamente, la nupcialidad influye sobre la determinación del tiempo de exposición de la mujer al riesgo de concebir, el cual, dados los supuestos que se acaban de mencionar, equivale al tiempo que la mujer pasa en unión durante su periodo fértil.

El propósito del presente trabajo es analizar las características asociadas a la formación y disolución de las uniones, en términos de la naturaleza o tipo de unión que contraen las mujeres. Se postula como hipótesis que la edad a la primera unión, la proporción de uniones disueltas y la propensión a contraer nuevas nupcias son diferentes según se trate de uniones legales (matrimonios) o uniones de hecho (convivencias). Estas distintas pautas de nupcialidad definirían diferentes duraciones de uniones con niveles de fecundidad también diferenciados.

Los datos de la encuesta de fecundidad rural, realizada en México hacia fines de 1969 y comienzos de 1970, ${ }^{11}$ permiten efectuar un análisis de las características de la nupcialidad de las mujeres que habitaban en localidades de menos de 20000 habitantes a comienzos de este decenio. Además del interés que representa el estudio de la nupcialidad en sí mismo, está el hecho de que la información recabada en esta encuesta tiene el valor

1 Encuesta realizada en México como parte del programa de encuestas comparativas de fecundidad en áreas rurales y semiurbanas de América Latina (PECFAL-R) bajo el auspicio de CELADE, El Colegio de México y el Instituto de Investigaciones Sociales de la UNAM. 
de haber sido obtenida justo antes de que se adoptara como una de las políticas de población oficiales, el logro de un descenso de la tasa de crecimiento de la población.

Por estas razones, las modificaciones (en especial las de índole demográfica) que se verifiquen a nivel de los sectores rurales y semi-urbanos, en adelante deberán examinarse con referencia a la situación constatada en los análisis referentes a esta encuesta.

Las tres mil mujeres entrevistadas constituyen una muestra autoponderada de la población femenina rural y semiurbana que contaba entre 15 y 49 años de edad, al comenzar el año $1970 .{ }^{2}$ Se trata de sobrevivientes de las generaciones nacidas entre los años 1920 y 1954 que de haber migrado alguna vez fuera de las localidades de menos de 20000 habitantes, regresaron a ellas.

El hecho de que las entrevistas pertenezcan a diferentes generaciones impone al análisis las limitantes de una información de carácter retrospectivo. Es decir, se atribuye a las mujeres que murieron o que emigraron antes de la fecha de la encuesta un comportamiento, con respecto a la nupcialidad, similar al de las entrevistadas. A estos supuestos deben agregarse los relativos a una mortalidad semejante entre solteros y unidos y el de una migración no selectiva por estado civil. El efecto de una mayor mortandad entre los solteros conduce a una cierta sobrestimación de la nupcialidad producto de que en una misma generación las proporciones de solteros disminuyen por esta causa, más rápido que las de aquellos que están en unión. En el caso de la migración, el supuesto es más arriesgado desde el momento que una migración selectiva por estado civil puede modificar la estructura del mercado matrimonial, con posibles repercusiones sobre la edad al unirse, así como sobre la ruptura de uniones, la propensión a contraer nuevas uniones, e incluso sobre la intensidad del celibato definitivo.

Las interferencias entre los fenómenos de nupcialidad, mortalidad y migración que se acaban de mencionar, impiden establecer una correspondencia estricta entre la experiencia observada respecto de las mujeres interrogadas en una encuesta de tipo retrospectivo y la de las generaciones a las cuales pertenecen. Sin embargo, los problemas más importantes que pudieran derivarse del análisis de este tipo de información resultan de errores en el muestreo o de la mala calidad de la información obtenida, más que de las interferencias, las cuales en realidad conducen a la obtención de una medida menos pura del fenómeno en estudio.

Una forma de asegurar la confiabilidad de los datos, al margen de los problemas de interferencia que existen, consiste en compararlos con la información censal. A este efecto, y dada la coincidencia entre el periodo que se levantó la encuesta y la fecha del Censo de Población de 1970, se com-

2 Se efectuó una proyección de la población total al 30 de octubre de 1969 con los datos del censo de 1970 que sirvió de base para la obtención de la muestra utilizada. 
para la distribución por estado civil en ambas fuentes. En adición, se incluye un análisis de los datos censales sobre estado civil por tamaño de localidad, cuyo propósito es servir como referencia al estudio más específico de las características de la nupcialidad en los sectores rurales y semi urbanos de la encuesta.

La segunda parte está dedicada al análisis de la información sobre nupcialidad, relativa al grupo de mujeres de la encuesta que hubieran contraído al menos una unión. Este análisis abarca el estudio de la edad a la primera unión, del número de uniones, de la causa de disolución y tiempo pasado en unión (duración de uniones) en función de la naturaleza de la unión actual o última, según se trate de mujeres con uniones subsistentes o interrumpidas en la fecha de la entrevista.

Por último, se examina la naturaleza de la unión y, en algunos casos, la edad media al contraer la primera unión por parte de las entrevistadas en función esta vez del contexto en que habitan (grado de ruralidad del lugar y región del país) y de algunas de sus características socioeconómicas (educación y ocupación).

\section{Distribución de las mujeres por estado civil en LA ENCUesta Y EN EL CENSO}

Según datos censales, en 1970 el $64.7 \%$ de la población total del país vivía en localidades de menos de 20000 habitantes. De los 10.7 millones de mujeres en edades reproductivas en 1970, 6.6 millones habitaban en lugares rurales o semiurbanos. El componente rural de esta población se ve acrecentado si se considera que el $61.8 \%$ de ella habitaba en localidades de menos de 2500 habitantes. Conforme al sentido estricto de la definición censal mexicana, sólo las mujeres de este último grupo serían rurales; en otros países, el límite entre lo rural y lo urbano se establece en 20000 habitantes (se incluye entre la población rural la que en México se considera como semiurbana - 2500 a 19999 habitantes).

En la encuesta de Fecundidad Rural de la cual provienen la gran mayoría de los datos que se analizan en este trabajo, la población rural se dividió en dos estratos. Esta división se hizo teniendo en cuenta la existencia o no, en el municipio de la unidad primaria de muestreo, de localidades de 20000 habitantes o más. De esta forma se pueden distinguir en la encuesta un total de tres grupos de mujeres según el grado de urbanización del lugar en que habitan: $a$ ) aquellas que viven en localidades de menos de 2500 habitantes pero próximas a centros urbanos; $b$ ) aquellas que viven en localidades de menos de 2500 habitantes pero sin influencia urbana, $\mathrm{y} ; c)$ aquellas que viven en localidades cuyo número de habitantes oscila entre los 2500 y 19999.

La importancia relativa del grupo de mujeres en edades reproductivas que viven en localidades de menos de 20000 habitantes (61.5\% del total 
del país) evidencia la influencia que tiene su comportamiento reproductivo sobre los niveles generales de la fecundidad en México.

Esta misma razón da relevancia al análisis de la nupcialidad como uno de los componentes que incide más de cerca sobre las pautas reproductivas de una población que, por lo menos hasta 1970 , no ejercía un control efectivo de su fecundidad. ${ }^{8}$ Cuando una población se comporta conforme a un régimen de fecundidad natural, la edad al contraer la primera unión y la duración de ésta son factores fundamentales del nivel que alcanza la fecundidad.

Como ya se mencionó antes, al estudio de la nupcialidad en la encuesta de fecundidad rural, antecede una comparación entre los datos sobre estado civil derivados de la propia encuesta y aquellos provenientes del censo de población de 1970. Con ésto se persigue un doble fin, el de validar la información de la encuesta que va a ser utilizada a lo largo de este trabajo, recurriendo para ello a una fuente externa como es el censo y el de ofrecer un panorama de la distribución por estado civil a nivel nacional.

En el cuadro 1, figuran las distribuciones por estado civil de las mujeres de 15 a 49 años de edad en la encuesta y el censo de población de 1970. Al no haberse tabulado en este último los datos por estado civil en forma que pudiera identificarse al grupo de mujeres de 15 a 49 años para las localidades de menos de 20000 habitantes, fue necesario comparar la población de la encuesta, es decir, las mujeres de 15 a 49 años en localidades de menos de 20000 habitantes, con el grupo de mujeres de 15 a 49 años para el conjunto del país.

En las áreas rurales y semiurbanas, las solteras representaron poco más de un cuarto de la población de 15 a 49 años (26\%) y las mujeres que estaban unidas al momento de la entrevista, alcanzaron al $67 \%$. Completa esta repartición el grupo de mujeres viudas, separadas, o divorciadas $(6.8 \%)$. La proporción de "no respuesta" fue mínima $(0.2 \%)$.

Las costumbres y las propias disposiciones legales han impuesto una gama de arreglos matrimoniales que permiten dividir el conjunto de mujeres que han contraído al menos una unión (actualmente unidas y con uniones interrumpidas) según la naturaleza que éstas revistan. En el caso que nos ocupa (datos del cuadro 1) la naturaleza de unión retenida fue la correspondiente a la de la unión en que se encuentra la mujer o en su defecto, la última que tuvo.

La naturaleza de unión más frecuente entre las mujeres de la encuesta es el "matrimonio civil y religioso" que es aquel que obtiene sanción legal y de la iglesia. El $42.2 \%$ de las mujeres se declararon unidas en este tipo de unión. Además, por la forma en que se definió esta categoría, se incluye a aquellas mujeres que se encuentran "unidas sólo por la iglesia". A diferencia del censo, en la encuesta no se estableció una categoría aparte

\footnotetext{
3 En un trabajo anterior sobre esta misma encuesta se demostró que se trataba de una población en régimen de fecundidad natural. J. Quilodrán, "Algunas características de la fecundidad rural en México" (en prensa).
} 
Cuadro 1

MÉxico: Mujeres de 15 a 49 años SEgứn ESTAdo CIVIL EN LOCALIDADES DE MENOS DE 20000 HABITANTES Y PARA EL PAÍ́ EN CONJUNTO, 1970

(miles de personas)

\begin{tabular}{|c|c|c|c|c|c|}
\hline \multirow{2}{*}{ Estado civil } & \multicolumn{2}{|c|}{ En localidades de 20000} & \multicolumn{3}{|c|}{ Total de1 pais } \\
\hline & Número & $\stackrel{0}{\square}$ & & Wamero & 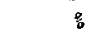 \\
\hline Solteras & 781 & 26.0 & & 484.7 & 32.5 \\
\hline Actua1nente unidas & 2008 & 67.0 & 6 & 679.1 & 62.3 \\
\hline $\begin{array}{l}\text { Matrimonio sólo civil } \\
\text { Matrimonio civil y religioso } \\
\text { Matrimonio sólo religioso } \\
\text { Convivencia }\end{array}$ & $\begin{array}{l}1339 \\
1266 \\
403\end{array}$ & $\begin{array}{l}11.3 \\
42.4 \\
-13.4\end{array}$ & & $\begin{array}{l}054.2 \\
039.7 \\
511.0 \\
074.2\end{array}$ & $\begin{array}{r}9.8 \\
37.7 \\
4.8 \\
10.0\end{array}$ \\
\hline Uniones interrumpidas & 203 & 6.8 & & 554.8 & 5.2 \\
\hline $\begin{array}{l}\text { Viudas } \\
\text { Matrimonio sólo civil } \\
\text { Matrinonio civil y religioso } \\
\text { Convivencia } \\
\text { separadas } \\
\text { Matrimionsóno civil } \\
\text { tatrimonio civil y religioso } \\
\text { Convivencia } \\
\text { Divorciadas }\end{array}$ & 125 & $\begin{array}{l}2.4 \\
0.5 \\
1.5 \\
0.4 \\
4.2 \\
0.5 \\
1.2 \\
2.5 \\
0.1\end{array}$ & & .234 .5 & 2.5 \\
\hline Sin respuesta & 7 & 0.2 & & - & - \\
\hline Totál & 2999 & 100.0 & 10 & 718.7 & $100^{\circ} .0^{\circ}$ \\
\hline Mujeres alguna vez unidas & 2211 & 73.7 & 7 & 234.0 & 67.5 \\
\hline
\end{tabular}

FUENTE: Los datos para las localidades de menos de 20000 habitantes provienen de la Encuesta de Fecundidad Rural ( $P E C F A L$-México) y para el conjunto del país del Censo de Población de 1970.

para el matrimonio que sólo recibe reconocimiento religioso. De haberse hecho, se habría dispuesto de información sobre las características de la gran mayoría de las mujeres que la conforman, ya que según los datos censales para 1970, el $84 \%$ de las mujeres de 12 años y más unidas sólo en matrimonio religioso, viven justamente en las localidades de menos de 20000 habitantes. Esta categoría de estado civil ha subsistido a través del tiempo, aunque con una importancia relativa en disminución.

Si a la categoría de matrimonio "civil y religioso" se suma la de los matrimonios "sólo civiles" (11.3\%) el conjunto de mujeres unidas legalmente alcanza al $53.5 \%$ del total de mujeres entrevistadas en la encuesta. Sin embargo, esta cifra está lejos de abarcar el total de mujeres entrevistadas que llevan vida marital. Un $13.4 \%$ de ellas se declara en convivencia (unión libre), con lo cual la proporción de mujeres en unión se eleva al $66.9 \%$ del total de mujeres que tienen entre 15 y 49 años de edad. 
Si se considera ahora la distribución censal que figura en el mismo cuadro 1 , se observa de inmediato una diferencia importante entre las proporciones de solteras de la encuesta y del censo. La cifra de solteras a nivel del conjunto del país (32.5\%) es $25 \%$ mayor que la que se obtiene para la localidades de menos de 20000 habitantes $(26 \%)$.

Como una forma de distinguir, en las proporciones de solteras, las diferencias que pudieran resultar de pautas diferentes de nupcialidad urbana por un lado, y semiurbana y rural por otro (edad al casarse más tardía, celibato definitivo más elevado) de aquellas que pudieran ser producto de errores de muestreo, o de declaración del estado civil, se calculó a partir de datos censales la población femenina soltera de 15 a 49 años para localidades de menos de $20000.4 \mathrm{La}$ cifra obtenida fue de $30.6 \%$ de solteras, con lo cual la diferencia entre la proporción censal y la de la encuesta se ve reducida pero no desaparece. Esta discrepancia puede ser atribuida a una subrepresentación de los grupos de edades más jóvenes (15-19 y 20-24 años) que existe en la encuesta. ${ }^{5} \mathrm{El}$ hecho de que sea justamente en estos grupos donde se concentra la mayoría de las solteras explicaría que su proporción en la encuesta sea más reducida que la que se observa en el censo.

La proporción comparativamente menor de solteras en los grupos de edades de 15 a 49 años en el medio rural y semiurbano, acarrea en forma complementaria una mayor proporción de mujeres alguna vez unidas en este medio. A pesar de esto, la distribución por estado civil al interior de este último grupo es semejante en el censo y en la encuesta. En el caso del grupo de mujeres con uniones actuales, el predominio corresponde en ambas fuentes de datos a las uniones legales (matrimonios sólo civiles y civiles y religiosos).

En cuanto al conjunto de mujeres con uniones interrumpidas, éste es más numeroso en el sector semiurbano y rural que a nivel nacional. Esto significa que la ruptura de uniones es más frecuente a nivel rural y semiurbano que a nivel urbano o bien que este tipo de uniones fue mejor captado en la encuesta que en el censo. La propia naturaleza de las encuestas en que se realizan entrevistas más prolongadas y con personal más entrenado hace presumir que el nivel de las uniones disueltas corresponde más bien al obtenido para las localidades de menos de 20000 habitantes.

Con base en los datos anteriores, las mujeres en edad fértil pueden ser ordenadas de acuerdo con la importancia relativa de la categoría de estado civil a la que pertenecen: a) mujeres casadas por lo civil y religioso (incluidas aquellas en matrimonio sólo religioso) $(42 \%) ; b$ ) mujeres solteras (casi $30 \%) ; c$ ) mujeres en convivencia $(10 \%) ; d$ ) mujeres ca-

4 Véase en el Anexo 1 el procedimiento seguido para la estimación de las mujeres solteras de 15 a 49 años.

5 Guadalupe Espinoza y C. Welti, "Características generales de las entrevistadas de la Encuesta de Fecundidad Rural", Mimeo., cuadro 3, p. 8. 
sadas sólo por lo civil $(10 \%) ; e$ ) mujeres en uniones interrumpidas (viudas, separadas y divorciadas) (5\% a nivel del conjunto del país y casi $7 \%$ a nivel rural).

La información contenida en la encuesta sobre las uniones interrumpidas permite análisis más detallados. En el cuadro 2 se incluye la información disponible sobre el tipo de ruptura de unión y la naturaleza de última unión. Según estos datos, del conjunto de mujeres alguna vez unidas, $3.3 \%$ son viudas, $5.7 \%$ separadas y $0.2 \%$ divorciadas, lo cual arroja un total de $9.2 \%$ de mujeres en uniones disueltas.

\section{Cuadro 2}

MUJERES DE 15 a 49 aÑos CON UNIONES INTERRUMPIDAS SEGÚN CAUSA DE DISOLUCIÓN Y NATURALEZA DE LA ÚLTIMA UNIÓN

\begin{tabular}{|c|c|c|c|c|c|c|}
\hline \multirow{2}{*}{$\begin{array}{l}\text { Naturaleza de la } \\
\text { ultima unión }\end{array}$} & \multirow{2}{*}{$\begin{array}{l}\text { Actunlmente } \\
\text { u nidas }\end{array}$} & \multicolumn{5}{|c|}{ Uniones interrumpidas } \\
\hline & & Viudas & Separadas & Divorciadas & Suma & Total \\
\hline \multicolumn{7}{|l|}{$\begin{array}{l}\text { Matrimonio solo ci- } \\
\text { vil }\end{array}$} \\
\hline Súme ro & $\begin{array}{r}3.39 \\
98.6\end{array}$ & $\begin{array}{r}15 \\
4.0\end{array}$ & 4.5 & $\begin{array}{r}4 \\
1.1\end{array}$ & $\begin{array}{r}35 \\
9.4\end{array}$ & $\begin{array}{r}374 \\
100.0\end{array}$ \\
\hline \multicolumn{7}{|l|}{$\begin{array}{l}\text { Matrimonio civil y } \\
\text { religioso }\end{array}$} \\
\hline 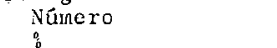 & 1266 & $=40$ & 35 & - & 81 & 1347 \\
\hline \multicolumn{7}{|l|}{ Convivencia } \\
\hline Núne ro & $\begin{array}{r}405 \\
82.2\end{array}$ & $\begin{array}{r}1.3 \\
2.7\end{array}$ & $\begin{array}{r}74 \\
15.1\end{array}$ & - & 17.87 & $\begin{array}{r}490 \\
100.0\end{array}$ \\
\hline \multicolumn{7}{|l|}{ Total } \\
\hline Número & $\begin{array}{r}2008 \\
90.8\end{array}$ & $\begin{array}{r}74 \\
3.3\end{array}$ & $\begin{array}{l}125 \\
5.7\end{array}$ & $\begin{array}{r}4 \\
0.2\end{array}$ & $\begin{array}{l}203 \\
9.2\end{array}$ & $\begin{array}{l}2211 \\
100.0\end{array}$ \\
\hline
\end{tabular}

Fuente: Encuesta PECFal.

La importancia relativa de este último grupo depende de varios factores, entre los cuales cabe mencionar: los niveles de la mortalidad masculina (entre más elevados sean éstos comparados con los de la mortalidad femenina, mayor será el número de mujeres que enviudan); la diferencia de edades entre los cónyuges (si por lo general la edad del esposo es más elevada que la de la esposa, cuanto más grande sea esta diferencia mayor será la probabilidad del esposo de morir antes); la frecuencia con la cual se dan las separaciones y divorcios de las parejas; así como la frecuencia con la cual contraen nuevas uniones las viudas, separadas y divorciadas.

Los datos del cuadro 2 muestran, además, que la ruptura de uniones por separación de hecho de los cónyuges es más frecuente que la ruptura por viudez y que prácticamente no se recurre, a nivel rural, al divorcio para poner fin a una unión. 
Estos mismos datos marcan tendencias diferenciales por naturaleza de la última unión. La frecuencia de disolución de uniones es mucho mayor entre las convivientes $(17.8 \%)$ que entre las mujeres en matrimonio sólo civil $(9.4 \%)$ y matrimonio civil y religioso $(6 \%)$. Ahora, si se consideran por separado las viudas y las separadas según tipo de unión última, se observa que la naturaleza de unión con menos viudas es la de las convivientes. La situación se da a la inversa en el caso de las separaciones donde la proporción de separadas de convivencia $(15.1 \%)$ es más de tres veces superior a la de separadas de matrimonio civil (4.3\%), y el doble de la de matrimonio civil y religioso. En conjunto hay más viudas provenientes de uniones legales que separadas de dichas uniones.

La menor proporción de viudas de convivencia, difícilmente se puede explicar por una menor mortalidad de las mujeres convivientes o por su mayor propensión a la unión, ya que esta misma propensión debería darse para las mujeres separadas cuyo nivel, como se vio, es el más elevado. Cabría preguntarse aquí, si la menor proporción de viudas de convivencia no está ligada a la alta proporción de separadas de convivencia; en el sentido de que una vez ocurrida la separación - que acontece en general a edades más tempranas que la viudez- la mujer continuaría declarándose en ese estado civil aun cuando el cónyuge haya fallecido. Este efecto tendría menor impacto sobre los otros tipos de unión en la medida que las separaciones son menos abundantes en ellas.

\section{Distribución DE LAS MUJeRes POR eStado CIVIL SEgún taMaño DE LA LOCALIDAD}

Como se mencionó en el punto anterior, en las diferencias observadas entre las distribuciones por estado civil a nivel nacional y de las localidades rurales y semiurbanas están implícitas diferencias urbano-rurales, cuyo análisis ha parecido importante ampliar. Para ello, se ha recurrido a datos censales sobre distribución por estado civil y tamaño de localidad. Esta información existe para el conjunto de mujeres de 12 años y más sin distinción de grupos de edades. La ausencia de clasificación por grupos de edades fue el motivo que impidió efectuar la comparación directa entre la información censal y de la encuesta para mujeres entre los 15 y 49 años de edad.

Los datos censales fueron reagrupados en las cuatro categorías que aparecen en el cuadro 3 , de modo de distinguir localidades rurales (2 500 habitantes), semiurbanas (2 500 a 19999 habitantes), urbanas de tamaño intermedio (entre 20000 y 49999 habitantes) y urbanas de 50000 habitantes y más. Esta última categoría representaba en 1970 el $38.9 \%$ de la población total del país y de ella el $56.8 \%$ vivía en ciudades de más de un millón de habitantes $\left(22.1 \%\right.$ de la población total del país), ${ }^{6}$ pero no

6 L. Unikel, C. Ruiz Chiapetto y G. Garza, El desarrollo urbano de México, México, El Colegio de México, 1976, cuadros 1-4, p. 30. 
Cuadro 3

MÉXICO: Distribución de LAS MUJJERES DE DOCE Y MÁs AÑoS SEGÚN ESTADO CIVIL Y TAMAÑo DE LA LOCALIDAD, 1970

\begin{tabular}{|c|c|c|c|c|c|}
\hline \multirow{2}{*}{ Estado civil } & \multicolumn{4}{|c|}{ Tamaño de la localidad } & \multirow{2}{*}{ Tota 1} \\
\hline & $\begin{array}{l}\text { Hasta } \\
2499\end{array}$ & $\begin{array}{l}2500 \mathrm{a} \\
19 \quad 999\end{array}$ & $\begin{array}{cc}20 & 000 \\
49 & 999\end{array}$ & $\begin{array}{c}50 \text { 000 } \\
y \text { más }\end{array}$ & \\
\hline Solteras & 32.6 & 37.3 & 39.2 & 41.0 & 36.8 \\
\hline Matrimonio civil & 8.1 & 7.8 & 8.1 & 8.0 & 8.0 \\
\hline Matrimonio religioso & 7.6 & 3.7 & 2.4 & 1.7 & 4.5 \\
\hline Civil y religioso & 32.2 & 35.2 & 34.2 & 32.5 & 33.2 \\
\hline Union libre & 11.8 & 7.2 & 6.3 & 5.5 & 8.4 \\
\hline Viudas & 5.8 & 6.3 & 6.7 & 7.2 & 6.5 \\
\hline Divorciadas & 0.4 & 0.4 & 0.7 & 1.1 & 0.6 \\
\hline Separadas & 1.5 & 2.1 & 2.4 & 3.0 & 2.0 \\
\hline Total $\left(\frac{g}{b}\right)-$ & 38.3 & 23.6 & 7.3 & 30.7 & 100.0 \\
\hline
\end{tabular}

Fuente: Dirección General de Estadística, Censo General de Población, 1970, México, Secretaría de Industria y Comercio.

a Mujeres de 12 y más años.

exista la clasificación censal por estado civil que permita separar este tamaño de localidad del resto.

Al comparar la distribución por estado civil del conjunto de las mujeres de 12 años y más (véase el cuadro 3 ) con la correspondiente a las mujeres de 15 a 49 años (véase cuadro 1), resalta la diferencia entre las proporciones de solteras a nivel nacional contenidas en ambos cuadros. La elevada proporción de solteras del cuadro 3 es producto de que se incluye, además de las mujeres de 15 a 49 años, a aquellas de 12 a 14 años, las cuales en su gran mayoría son solteras todavía a esas edades. Otra diferencia, resultante esta vez de la inclusión de mujeres de 50 años y más, es la mayor proporción de viudas; en cambio la proporción de mujeres separadas y divorciadas no se altera al tomar como referencia el grupo de mujeres de 12 años y más, en lugar del grupo de 15 a 49.

Al hacer la comparación entre tamaños de localidades para un mismo estado civil se observa, en el caso de las solteras, que esta categoría aumenta con el grado de urbanización. Como una forma de controlar el efecto de estructura por edades diferentes entre tamaños de localidades, se calcularon las proporciones de mujeres de 10 a 14 años sobre el total de la población de mujeres en cada uno de ellos. ${ }^{7}$ Las proporciones en-

7 La proporción de mujeres de 10 a 14 años con respecto al total de mujeres en cada tamaño de localidad es de $13.3 \%$ en localidades de menos de 2500 habitantes; $13.6 \%$ en localidades de 2500 a 19999 habitantes; $12.9 \%$ en localidades de 20000 a 49999 habitantes, y $12.3 \%$ en las localidades de 50000 y más. Se tomó como referencia el grupo de edades de 10 a 14 años por considerarse que en él la influencia de la nupcialidad no es importante. Datos del Censo de Población, 1970, cuadro 5. 
contradas son muy similares, lo que lleva a atribuir las diferencias en las proporciones de solteras, a distintas edades a la primera unión en cada tamaño de localidad, las cuales serían tanto más tardías cuanto más urbana sea la población en cuestión.

Para el resto de las categorías de estado civil, la situación comparativa por tamaños de localidad es la siguiente: una misma proporción de mujeres unidas "sólo en matrimonio civil" (8\%); una concentración de los matrimonios "sólo religiosos" en localidades rurales, ${ }^{8}$ situación ésta que se repite en el caso de las uniones "libres". Los matrimonios "civiles y religiosos" son algo más frecuentes (alrededor de un 7\%) en las localidades semiurbanas (2500 a 19999 habitantes) y urbanas de tamaño intermedio (entre 20000 y menos de 50000 habitantes) que en las localidades rurales y urbanas de mayor tamaño. Por último, la proporción de mujeres viudas aumenta con el tamaño de la localidad lo mismo que la correspondiente a divorciadas y separadas.

Los mayores diferenciales entre tamaños de localidades se dan en las categorías de mujeres en matrimonio sólo religioso y en convivencia. Dada la naturaleza no legal de estas dos categorías, podría pensarse que una cobertura deficiente del Registro Civil impide en ciertos lugares la legalización del matrimonio. Sin embargo, la inexistencia de un diferencial entre tamaños de localidad en el caso de los matrimonios sólo civiles, lleva a descartar esta hipótesis y aceptar que los diferenciales observados en las categorías de matrimonio sólo religioso y convivencia, estarían respondiendo a condicionamientos de índole socioculturai, que serían los que definirían finalmente las distintas pautas de los arreglos matrimoniales.

El aumento que se observa en la proporción de viudas a medida que aumenta el grado de urbanización, acepta una gama de explicaciones, entre las cuales surge como la más plausible, la existencia de un subregistro de mujeres. Este subregistro aumenta con la edad de la mujer y con el grado de ruralidad, como se observa al analizar los índices de masculinidad según tamaño de la localidad. ${ }^{10}$ Este subregistro afecta más a la categoría de viudas por encontrarse concentrada en las edades más avanzadas. ${ }^{\text {"11 }}$ Esta explicación no descarta la influencia simultánea de otros factores que pudieran estar determinando el incremento de la proporción de viudas con el incremento del tamaño de la localidad. Entre ellos estaría: un diferencial menor, a nivel rural, entre las esperanzas de vida de los es-

8 La proporción de mujeres en uniones sólo religiosas disminuye de $7.6 \%$ a $1.8 \%$, lo que equivale a un descenso del $76.3 \%$ entre las localidades de menos de 2500 habitantes y aquellas de 50000 y más.

${ }^{9} \mathrm{El}$ descenso equivale a un $52.9 \%$ entre las localidades más rurales y más urbanas.

10 En el anexo 2 se presentan los índices de masculinidad por grupos de edades y tamaños de localidad para 1970 que fundamentan esta afirmación.

11 A partir de los 50 años la categoría de viudas es la única categoría de estado civil que se incrementa. De $9.8 \%$ en el grupo de edades de 45 a 49 años se convierte en un $47.1 \%$ en el grupo de edades de 75 a 79 años, Censo de Población, 1970 (cuadro 8). 
posos que haría desaparecer ambos cónyuges en forma casi simultánea; una sobremortalidad masculina a nivel urbano (esperanza de vida más corta del hombre que de la mujer) que redunda en una mayor sobrevivencia de la esposa convertida en viuda; una migración selectiva de viudas hacia los sectores urbanos.

La disolución voluntaria de las uniones (divorcios y separaciones), se incrementa continuamente con el grado de urbanización. Esta información aparece como contradictoria de lo que se concluyó del análisis de la distribución por estado civil de las mujeres de 15 a 49 años a nivel nacional (censo) y para las localidades de menos de 20000 habitantes (encuesta). En esa parte, se dijo que las separaciones eran más frecuentes a nivel rural; en cambio los datos analizados ahora por tamaño de localidad, muestran que la situación es a la inversa. Evidentemente la cifra censal global de separados y divorciados está muy por debajo de la que da la encuesta para el nivel rural $(2.7 \%$ y $4.3 \%)$. Lo más probable es que la causa de esto esté en que la categoría de separadas se introdujo en el censo por primera vez en 1970. Por este motivo, la respuesta censal posiblemente no fue tan buena como para las otras categorías de estado civil. La relación a mayor tamaño de localidad mayor proporción de uniones interrumpidas probablemente se da pero en niveles más elevados que los que ofrecen las cifras del censo de 1970.

\section{CaRacterísticas de La NUPCialidad de las MUJeres RURALES Y SEMIURBANAS}

Esta parte del trabajo está destinada al análisis de algunas características de la nupcialidad de las mujeres entrevistadas en la Encuesta de Fecundidad Rural de México. Esto significa que el análisis se circunscribe ahora a aquellas mujeres que vivían, al momento de levantarse la encuesta, en localidades de menos de 20000 habitantes.

Hasta aquí se ha podido constatar que la naturaleza de unión predominante es la legal, pero que las uniones de tipo consensual representan una proporción importante con respecto al conjunto de mujeres que han contraído al menos una unión (14.8\% a nivel nacional) y, que lo es aún más, si se adopta como referencia la población rural $(21 \%)$. Esto, acompañado de la diversidad de tipos de matrimonios que existen, incluso al interior de las uniones legales y religiosas (sólo civil, sólo religiosas, civiles y religiosas), pone de manifiesto la heterogeneidad de arreglos matrimoniales que prevalecen en la sociedad mexicana.

Teniendo en cuenta lo anterior, se van a estudiar en primer lugar las características de la nupcialidad para el conjunto de mujeres de 15 a 49 años y luego conforme a sus diferencias según la naturaleza de unión en que se encuentran, o de la última que hubieran contraído si se trata de viudas, separadas o divorciadas. 


\section{Edad a la primera unión y celibato}

\section{a) Características generales}

Los datos censales disponibles para 1970, permiten llevar la comparación entre el nivel nacional y el semiurbano y rural a características tales como: la edad media a la cual suelen unirse por primera vez las mujeres que llegan a contraer al menos una unión; la proporción de mujeres que se encuentran unidas a los 50 años; así como también la de aquellas que pueden considerarse en celibato definitivo a esa misma edad.

Para el conjunto del país, la tabla de nupcialidad femenina del momento indica para 1970 , una media de edad a la unión primera de 21.7 años. ${ }^{12}$ Esta misma edad para las mujeres de localidades de menos de 20000 habitantes, con base en los datos de la encuesta FERU, es de 18.2 años. La diferencia entre ambas edades es lo suficientemente amplia para poder concluir que las uniones se inician más tardías a nivel urbano. Por tratarse de medidas del momento no se puede distinguir si el diferencial responde a cambios en las tendencias recientes de la nupcialidad, o sea al comportamiento de las generaciones más jóvenes, o a pautas de nupcialidad que se arrastran desde hace ya más tiempo.

De cualquier manera, la edad al unirse debe ser bastante más elevada a nivel urbano, para que la media nacional alcance un diferencial de 3.5 años, con todo y el peso relativo del sector de población rural y semiurbano sobre la población total del país. Datos provenientes de la Encuesta de Migración al Área Metropolitana de la Ciudad de México (1970) ofrecen evidencias en este sentido: ${ }^{13}$ las mujeres nativas de 35 a 49 años de edad contrajeron su primera unión a los 21.3 años (media). Esta cifra comparada a la de 19 años que se obtiene para el mismo grupo de mujeres y para el mismo año en la Encuesta de Fecundidad Rural, arroja un diferencial medio de 2.3 años. ${ }^{14}$

La proporción de célibes permanentes (solteros a los 50 años) que se desprende de la tabla de nupcialidad de solteros (1970), de donde se obtuvo la edad media al unirse de 21.7 años, es de $6.7 \%$. Los datos de la tabla correspondiente a las áreas rurales y semiurbanas (mujeres pertenecientes al grupo de generaciones 1920-1934) arroja una proporción similar a la nacional $(6.8 \%)$. Esto significa que aun cuando existen diferencias entre los calendarios de la nupcialidad a nivel rural y urbano, la intensidad de este fenómeno es la misma en ambos sectores.

$\mathrm{Si}$ se comparan las proporciones de célibes mexicanas con las de otros países (véase el cuadro 4) se observa que por lo general no se alejan mucho de las imperantes en países europeos para las mismas generaciones. $\mathrm{La}$ intensidad de la unión se ha acrecentado en los países europeos, ya que

12 J. Quilodrán, "Tablas de nupcialidad para México" (Mimeo.).

13 Ana María Goldani, "Impacto de la inmigración sobre la población del Área Metropolitana de la ciudad de México", México, 1976, cuadro 14.

14 J. Quilodrán, loc. cit. 
Cuadro 4

Proporciones de célibes permanentes (mujeres) para México Y ALGUNOS PAÍses de EUROPA, ĀFrICA y ASIA

\begin{tabular}{|c|c|c|}
\hline País & $\begin{array}{c}\text { Gencraciones } \\
\text { o años }\end{array}$ & $\begin{array}{c}\text { Célibes } \\
\left(\frac{a}{0}\right)\end{array}$ \\
\hline$\frac{\text { México }}{(\text { ruriti) }}$ & $\begin{array}{c}1970 \\
1920-1934 a\end{array}$ & $\begin{array}{l}6.7 \\
6.8\end{array}$ \\
\hline Furopa & $\int_{1931}^{193}$ & $\begin{array}{r}4.0 \\
13\end{array}$ \\
\hline $\begin{array}{l}\text { Dinamarca } \\
\text { Francia } \\
\text { Gran Bretina } \\
\text { Irlanda } \\
\text { Suecia }\end{array}$ & 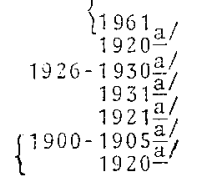 & $\begin{array}{r}9.2 \\
7.0 \\
7.4 \\
4.0 \\
20.0 \\
26.0 \\
7.0\end{array}$ \\
\hline $\begin{array}{l}\text { Africa } \\
\text { Arge1ia } \\
\text { Egipto } \\
\text { Marruccos } \\
\text { Scnegaj } \\
\text { Túnez }\end{array}$ & $\begin{array}{r}1966 \\
1960 \\
1971 \\
1970 \\
1966 \\
1975\end{array}$ & $\begin{array}{l}1.5 \\
2.0 \\
1.8 \\
5.0 \\
2.1 \\
1.6\end{array}$ \\
\hline$\frac{\Lambda \text { Sia }}{\text { Sri Lanka }}$ & 1971 & 3.6 \\
\hline
\end{tabular}

Fuentes: México: Datos del Censo de 1970 y Encuesta de Fecundidad Rural (PECFAL); Europa: Louis Roussel, "Le mariage dans la societé francaise", Cahier No. 73, INED, 1975, p. 41. Los datos para Bélgica fueron extraídos de Wattelar y Wuns, "La nuptialité en Belgique", Louvain, 1967 y Freedman, Davis y Blake, "Factores sociológicos de la fecundidad, El Colegio de México-CELADE, 1967; Africa: D. Tabutin, "Tables de nuptialité africaines", Ponencia UIESP, Lieja, 1973; Asia: Duza y Baldwin, "Nuptiality and Population Policy", Population Council, 1977.

a Generaciones.

como lo indican los datos disponibles para los años 30 (mujeres pertenecientes a generaciones nacidas a fines del siglo XIX) el celibato era entonces más elevado que en la actualidad. $\mathrm{Si}$ por el contrario se comparan las cifras mexicanas con las intensidades observadas en algunos países africanos, las de éstos resultan bastante más bajas. $\mathrm{O}$ sea, la universalidad del matrimonio o de la unión sería más grande en África que en Europa e incluso que en México.

b) Edad a la primera unión según naturaleza de la unión

Antes de presentar las edades a la primera unión para el conjunto y para cada naturaleza de la última unión se analizarán las proporciones de 


\section{Gráfica 1}

Proporciones aCUMUladas de MUJEREs unidas al MENOS UNA Vez, SEGÚN EDAD, AL CONTRAER LA PRIMERA UNIÓN CON RESPECTO AL TOTAL DE MUJERES, EN CADA GRUPO DE EDAD

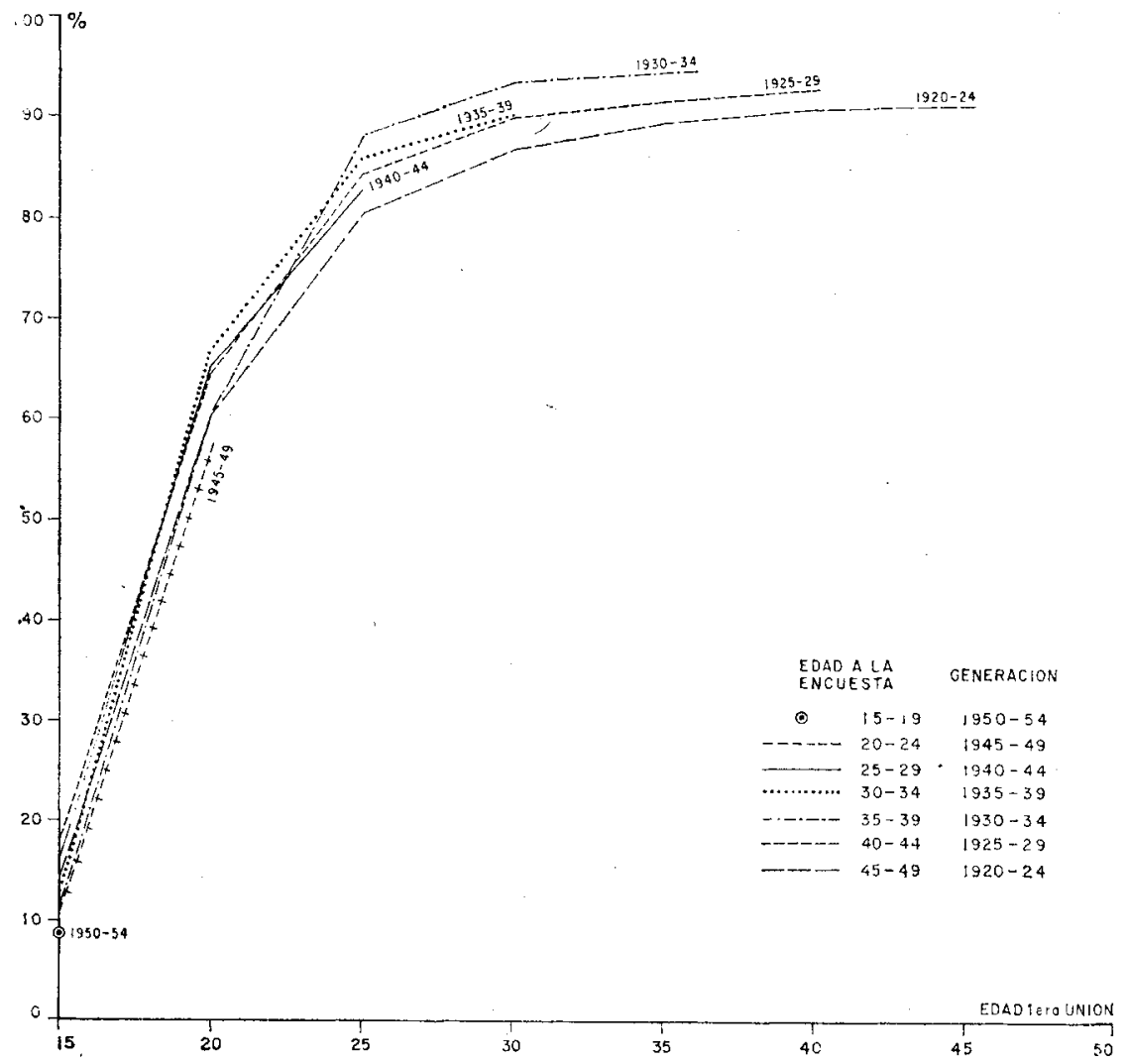


mujeres alguna vez unidas según edades al contraer la primera unión para cada uno de los grupos de generaciones.

El interés de un análisis generacional de los calendarios de las uniones reside en establecer si han sufrido variaciones a través del tiempo. Estas distribuciones resultan más ilustrativas que las edades medias al contraer la primera unión, a efecto de detectar cambios que pudieran estar ocurriendo en la nupcialidad.

Aun cuando el calendario, en sentido estricto, es una característica que se desprende de la tabla correspondiente al fenómeno estudiado - en este caso la tabla de nupcialidad de solteros-, la distribución de las primeras uniones por grupos de edad al interior de cada grupo de generaciones, constituye una buena aproximación de lo que sería el calendario de las tablas atribuibles a dichos grupos de generaciones.

En la gráfica $1^{15}$ se puede apreciar que las proporciones acumuladas de mujeres que se unen en cada grupo de edades con respecto al total de mujeres en cada uno de los grupos, es muy similar en todas las generaciones.

Antes de cumplir los 15 años se ha unido más o menos el $13 \%$ de las mujeres de un mismo grupo de generaciones; antes de los 20 el $60 \%$; a los 25 años el $80 \%$ y a los 35 años se ha alcanzado prácticamente la proporción definitiva de mujeres que contraen al menos una unión. En el caso del México rural, esta proporción supera el $90 \%$. Las cifras anteriores resumen aproximadamente el comportamiento del conjunto de mujeres entrevistadas.

Comparando los grupos de generaciones entre sí no se advierten cambios de importancia en los niveles de la nupcialidad alcanzados a las distintas edades. La edad modal a la unión es de 15 años. A partir de los 30 años el incremento de las proporciones es mínimo. En los dos grupos de generaciones más jóvenes (1950-1954 y 1945-1949) las proporciones de mujeres unidas antes de los 15 y 20 años son algo más bajas que en las generaciones más antiguas; sin embargo, no es posible afirmar, con un número tan escaso de observaciones, que se está produciendo un retraso en la edad de contraer la primera unión.

Por otra parte, en el cuadro 5 figuran las edades medias para el conjunto y para cada una de los tipos de unión (según su naturaleza) de las mujeres que han contraído al menos una unión a la fecha de la entrevista. En cada caso se ha calculado la edad correspondiente al grupo de mujeres de 15 a 49 años y aquella restringida al grupo de mujeres de 35 a 49 años. En estricto sentido, la edad media debe reflejar la experiencia de una generación o grupo de generaciones una vez que éstas hayan rebasado la edad más allá de la cual se considera que la probabilidad de contraer una primera unión es casi nula (50 años). Dado que en la encuesta el número de primeras uniones después de los 35 años es muy escaso, se procedió a calcular la edad media para el grupo de mujeres de 35 a 49 años, además de la edad correspondiente al conjunto.

15 En el anexo 3, cuadro 1 aparecen los datos correspondientes a esta gráfica. 


\section{Cuadro 5}

EDADES MEDIA Y MODAI, A LA PRIMERA UNIÓN DE LAS MUJERES ALGUNA VEZ UNIDAS, SEGÚN NATURALEZA DE LAS UNIONES

\begin{tabular}{lccc} 
Naturaleza de la última unión & \multicolumn{2}{c}{ Edades medias } & Edad modal \\
\hline Matrimonio sólo civil & $15-49$ & $35-49$ & 15 \\
Matrimonio civil y religioso & $(37.0$ & 19.3 & $101)$ \\
Convivencia & 18.6 & 19.2 & 17 \\
Total & $(1347)$ & $(588)$ & 15 \\
& $(17.4$ & 18.1 & 15 \\
\end{tabular}

a Las cifras entre paréntesis corresponden al número de casos.

La edad media al contraer la primera unión entre las mujeres de 15 a 49 años es de 18.2 años. Ahora bien, si las generaciones nacidas entre 1935 y 1954 ( 15 a 35 años al momento de la entrevista) repiten exactamente la experiencia matrimonial de las generaciones 1920-1934 (35 a 49 años), su edad media terminará siendo también de 19 años.

En la gráfica $2^{116}$ se han representado las distribuciones porcentuales según la edad al contraer la primera unión de 100 mujeres pertenecientes a cada una de las tres naturalezas de uniones que se han venido distinguiendo (matrimonio sólo civil, civil y religioso y convivencia).

Existe un desfase entre las tres curvas que refleja qué tan joven y qué tan rápido se unen las mujeres que lo hacen en matrimonio sólo civil, en civil y religioso y en convivencia. Sin lugar a dudas la unión que se celebra a edades más precoces es la convivencia o unión libre, pues alcanza su frecuencia máxima a los 15 años cuando ya se ha unido el $26.2 \%$ del total. El matrimonio sólo civil se diferencia del civil y religioso en que alcanza su máximo más rápido (edad modal 15 años, igual que la convivencia); así, se tiene que a los 15 años el $16 \%$ ya se ha unido al menos una vez mientras que entre las mujeres que se casan civil y religiosamente a esa misma edad la proporción es del $13.8 \%$. La edad modal es en el caso de este último tipo de unión de 17 años, es decir 2 años más elevada que en los otros dos.

A los 20 años, de 100 mujeres unidas al momento de la entrevista, en matrimonio sólo civil 78.7 ya se habían unido, 71 en el caso de las casadas en matrimonio civil y religioso y 83.3 tratándose de convivientes. Como se observa, a los 20 años las diferencias entre proporciones de unidas según tipo de unión son apreciables; sin embargo, a los 25 aunque persisten ya son pequeñas. Después de los 25 se une todavía entre un 4 y $6 \%$ del total de mujeres que llegan a contraer al menos una unión.

16 Anexo 3, cuadro 2, datos correspondientes a la gráfica 2. 
Gráfica 2

MUJERES ALGUNA VEZ UNIDAS DE 15 A 49 AÑOS, SEGÚN EDAD, AL CONTRAER LA PRIMERA UNIÓN Y NATURALEZA DE UNIÓN (100 mujeres en cada naturaleza de unión)

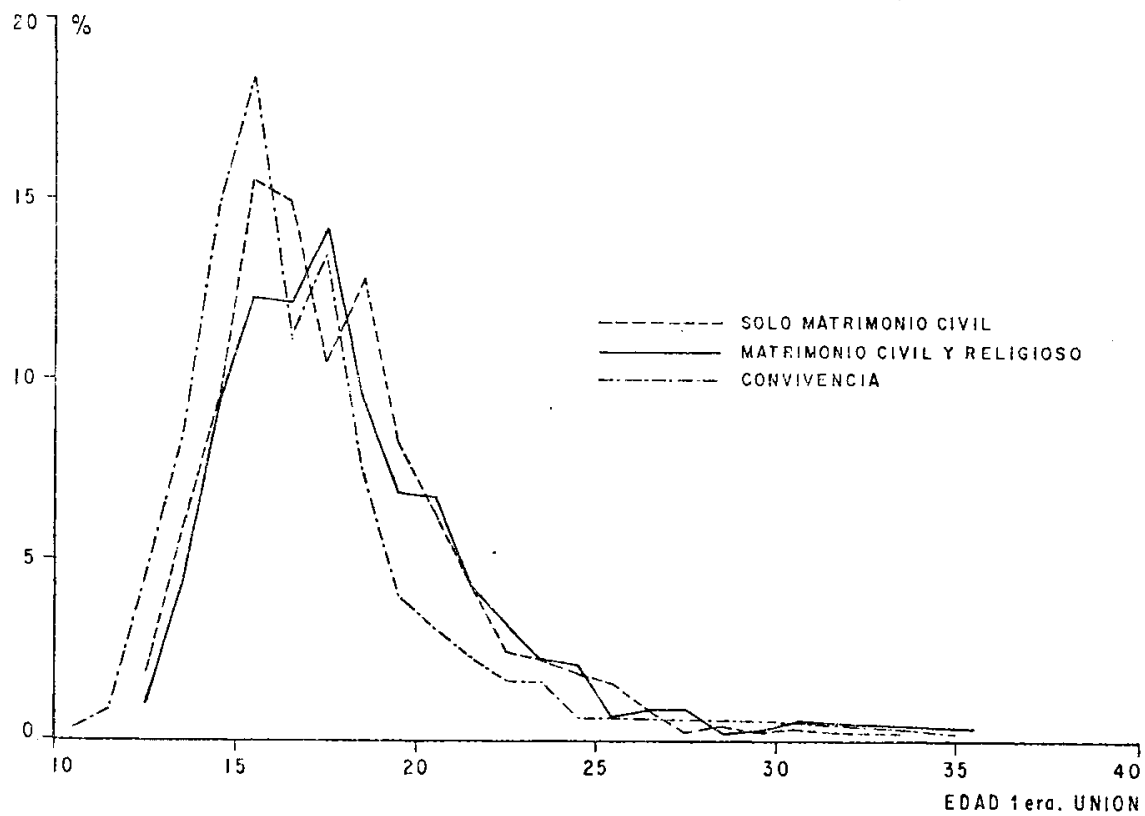

Las distribuciones contenidas en la gráfica 2 permiten visualizar mejor las diferencias de comportamiento de las mujeres que se unen, en uno u otro tipo de unión, que las simples medias de edades que figuran en el cuadro 5. Cualquiera de los dos, la gráfica 2 o el cuadro 5, marcan una clara tendencia: la unión libre o consensual se contrae a edades más tempranas que la legal.

\section{Número de uniones}

a) Número de uniones y naturaleza de la última unión

Si se atiende en primer lugar al número de uniones, se observa que el $80.6 \%$ del total de mujeres alguna vez unidas sólo había contraído una unión hasta el momento de la entrevista. El 19.4\% restante se encuentra unida, en su gran mayoría, en una segunda unión $(17 \%)^{17}$ y sólo el $2.4 \%$ sobrepasa las dos uniones. El máximo de uniones registrado en la encuesta fue de cinco (véase el cuadro 6). Al comparar las cifras de Méxi-

17 Esta proporción incluye a las mujeres cuya segunda unión constituye en realidad una legalización de la primera unión. 
co con las de los otros países donde se levantaron encuestas de este mismo tipo, resulta que el único país que presenta una proporción superior al $20 \%$ de mujeres con dos o más uniones es Perú. ${ }^{18} \mathrm{Al}$ igual que en México, en Costa Rica, Perú y Colombia, las uniones de rango superior a dos es mínimo.

\section{Cuadro 6}

\section{DISTRIBUCIÓN DE LAS MUJERES ALGUNA VEZ UNIDAS SEGÚN NÚMERO DE UNIONES Y NATURALEZA DE LA UNIÓN ÚLTIMA}

(para 100 mujeres en cada naturaleza de unión)

\begin{tabular}{|c|c|c|c|c|c|}
\hline \multirow{2}{*}{$\begin{array}{l}\text { Naturaleza de la } \\
\text { unión últina }\end{array}$} & \multicolumn{4}{|c|}{ Número de uniones al } & \multirow{2}{*}{$\begin{array}{l}\text { júmero medio } \\
\text { de uniones }\end{array}$} \\
\hline & 1 & 2 & 3 y mäs & Teta] & \\
\hline Matrimonio sólo civil & $\begin{array}{l}81.19 \\
(307)\end{array}$ & $(64)$ & $\begin{array}{l}1.0 \\
(4)\end{array}$ & $\begin{array}{l}100.0 \\
(375)\end{array}$ & 1.19 \\
\hline $\begin{array}{l}\text { Matrimonio civil } \\
y \text { religioso }\end{array}$ & $\left(\begin{array}{ll}1 & 84.7 \\
140\end{array}\right)$ & $(13 i)^{13}$ & $(1 \dot{5})^{1}$ & $\begin{array}{r}100.9 \\
(1,346)\end{array}$ & 1.16 \\
\hline Convivencia & $\begin{array}{r}68.3 \\
(332)\end{array}$ & $\begin{array}{l}24.7 \\
(120)\end{array}$ & $\begin{array}{r}7.0 \\
(34)\end{array}$ & $\begin{array}{l}100.0 \\
(486)\end{array}$ & 1.40 \\
\hline Tota1 & $\left(i \begin{array}{l}80.6 \\
779\end{array}\right)$ & $\begin{array}{r}17.0 \\
(375)\end{array}$ & $\begin{array}{r}2.4 \\
(53)\end{array}$ & $\begin{array}{r}100.0 \\
(2 \quad 207)\end{array}$ & 1.22 \\
\hline
\end{tabular}

a Las cifras entre paréntesis corresponden al número de casos.

Los datos para México indican que el número de uniones no es independiente del último tipo de unión. En realidad, se advierte que existe una propensión a unirse más frecuentemente en convivencia a medida que se incrementa el número de uniones (véase el cuadro 6). Esto se traduce en un número medio de uniones más elevado para el grupo de mujeres que se encuentran en una convivencia o cuya última unión fue de este tipo (1.4 uniones). Las mujeres en matrimonio sólo civil o civil y religioso registran un comportamiento similar entre sí con un número medio de uniones que no supera el 1.2 en ambos casos.

b) Edad media al unirse según orden de la unión

La edad media al unirse por primera, segunda y tercera vez fue calculada para el conjunto de mujeres sin distinción del tipo de unión último (véase el cuadro 7).

La edad media correspondiente al grupo de mujeres que sólo han contraído una unión (18.5 años) es muy similar a la del conjunto (18.2

18 Marginales comparativos del Programa de Encuestas PECFAL-R, CELade, Santiago de Chile. Variable No. 388 (para mujeres casadas y convivientes): Costa Rica, $18 \%$; Perú, $28.5 \%$; Colombia, $19.6 \%$ y México, $19 \%$. 
años) debido a la preponderancia de las mujeres con una unión dentro de él. En cambio, la edad a la primera unión para las mujeres de 35 a 49 años que han tenido una sola unión es un año y medio más elevada que la del conjunto (20.5 y 19.0 años, respectivamente). Esto significa que al eliminar del cálculo de la edad a la primera unión gran parte de aquellas mujeres que llegan a contraer más de una unión, se tiene que las mujeres que se unen sólo una vez contraen esa unión a edades más tardías que el resto de las mujeres. Dicho de otra forma, las mujeres que se unen más jóvenes tienen propensión a unirse más veces.

\section{Cuadro 7}

EDAD MEDIA DE LAS MUJERES AL UNIRSE, SEGÚN ORDEN DE LA UNIÓN ${ }^{a}$

\begin{tabular}{|c|c|c|c|c|c|c|c|}
\hline \multicolumn{6}{|c|}{ Orden de la unión } & \multirow{2}{*}{\multicolumn{2}{|c|}{$\begin{array}{c}\text { Edad a 1a primera } \\
\text { union } \\
\text { (conjunto) }\end{array}$}} \\
\hline \multicolumn{2}{|c|}{1} & \multicolumn{2}{|c|}{2} & \multicolumn{2}{|c|}{3} & & \\
\hline $15-49$ & $35-49$ & $15-49$ & $35-49$ & $15-49$ & $35-49$ & $15-49$ & $35-49$ \\
\hline años & años & años & años & años & años & años & años \\
\hline $\begin{array}{l}18.5 \\
(1779)\end{array}$ & $\begin{array}{l}20.5 \\
(655)\end{array}$ & $\begin{array}{l}23.5 \\
(422)\end{array}$ & $\begin{array}{l}26.4 \\
(211)\end{array}$ & $\begin{array}{l}28.9 \\
(49)\end{array}$ & $\begin{array}{l}32.2 \\
(30)\end{array}$ & $\begin{array}{l}18.2 \\
(2 \quad 199)\end{array}$ & $\begin{array}{l}19.0 \\
(862)\end{array}$ \\
\hline
\end{tabular}

a Las cifras entre paréntesis corresponden al número de casos.

Según se adopte como referencia las edades medias correspondientes al conjunto de mujeres de 15 a 49 años o de 35 a 49 años, las diferencias entre las edades al contraer la primera, segunda y tercera unión oscilan entre 5 y 6 años.

Según estos mismos datos, las mujeres pertenecientes a localidades rurales y semiurbanas contraen su primera unión hacia los 19 años; quienes se unen más de una vez celebran su segunda unión alrededor de los 26 años y; quienes lo hacen tres o más veces, celebran su tercera unión a los 32 años. Estas medias corresponden a las pautas de nupcialidad imperantes en las generaciones que contaban entre 35 y 49 años cumplidos (generaciones 1920-1934) al momento de la encuesta. Es posible que estos mismos valores medios sean diferentes entre las generaciones más jóvenes pero se necesitaría un número de observaciones mayor para efectuar el análisis por generaciones que ello requiere.

La media general de 19 años de edad, dado que incluye las mujeres que se unen más de una vez (20\%), encubre el hecho de que la gran mayoría de estas mujeres (mujeres con una sola unión) se unen a edades más tardías cuya edad media viene a ser de 20.5 años. Esta afirmación se basa en la comparación entre la edad a la primera unión de las mujeres con una sola unión y la del conjunto de mujeres (20.5 y 19 años, respectivamente). 


\section{Duración de uniones}

La variable duración de uniones representa la suma de los años que cada mujer ha pasado unida al momento de la encuesta. En el caso de aquellas que han estado unidas más de una vez, no se computaron los intervalos entre uniones.

La intervención de las fechas de inicio y término de cada una de las uniones (o al menos la de inicio para las uniones subsistentes), en la definición de la duración de las uniones se tradujo en una elevada proporción de mujeres con duración de uniones no determinadas. Se calcula el mes de la unión para aquellas que habían declarado el año en que ésta ocurrió, la proporción mencionada se redujo al 8.7\%. Sin embargo, se observó que la "no respuesta" era selectiva; en primer lugar, según la edad (elevándose conforme ésta avanzaba) en segundo lugar, según la naturaleza de la unión y, por último, según se tratara de uniones subsistentes o interrumpidas.

En el caso de mujeres viudas, separadas y divorciadas, con una sola unión, la imposibilidad de calcularles la duración de uniones alcanzó al $100 \%$; esta misma cifra fue del $77 \%$ tratándose del conjunto de mujeres con una o más uniones. Al diferenciar la "no respuesta" por naturaleza de la unión se tiene que ésta es mucho mayor entre las convivientes (16\%) que entre aquellas mujeres en matrimonio sólo civil $(8.7 \%)$ y civil y religioso $(6.2 \%)$. Un comportamiento semejante se observa entre las mujeres con una sola unión: un total de $\mathbf{8 . 8 \%}$ de "duración indeterminada de uniones", también con diferencias según la naturaleza de la unión.

La elevada proporción de mujeres con uniones interrumpidas a las cuales no se les pudo calcular su duración de uniones, llevó a limitar el análisis a la duración de las uniones correspondientes al grupo de mujeres con uniones subsistentes. En este grupo la proporción de mujeres con duración de uniones no determinadas es de sólo $2 \%$.

En el cuadro 8 figuran los tiempos medios generales de duración de uniones según la naturaleza de la última unión. El número medio de años pasados en unión por el conjunto de mujeres con una o más uniones subsistentes es de 13.7 años. Este mismo número medio es algo más bajo (13.2 años) entre las mujeres que se encuentran en su primera unión.

Si se anula el efecto de las diferentes estructuras por edad según naturaleza de la unión última (medias estandarizadas) se tiene que las diferencias entre las duraciones de uniones prácticamente desaparecen, a diferencia de las que efectivamente se observan (medias generales). Sin eliminar el efecto de la edad, el tiempo medio de duración más bajo corresponde al matrimonio civil, le sigue la convivencia y finalmente el matrimonio civil y religioso. Esto significa que cada naturaleza de unión tiene su propia estructura por edades. Entre más vieja es esta estructura, mayor es el número de años de unión que han tenido tiempo de acumular las mujeres que la conforman. 


\section{Cuadro 8}

\section{DURACión MEdia dE UNIONES (AÑos) PARA MUJERES CON UNIONES}

SUBSISTENTES SEGÚN EDAD A LA ENTREVISTA $Y$ NATURALEZA

DE LA ÚlLTIMA UNIÓN

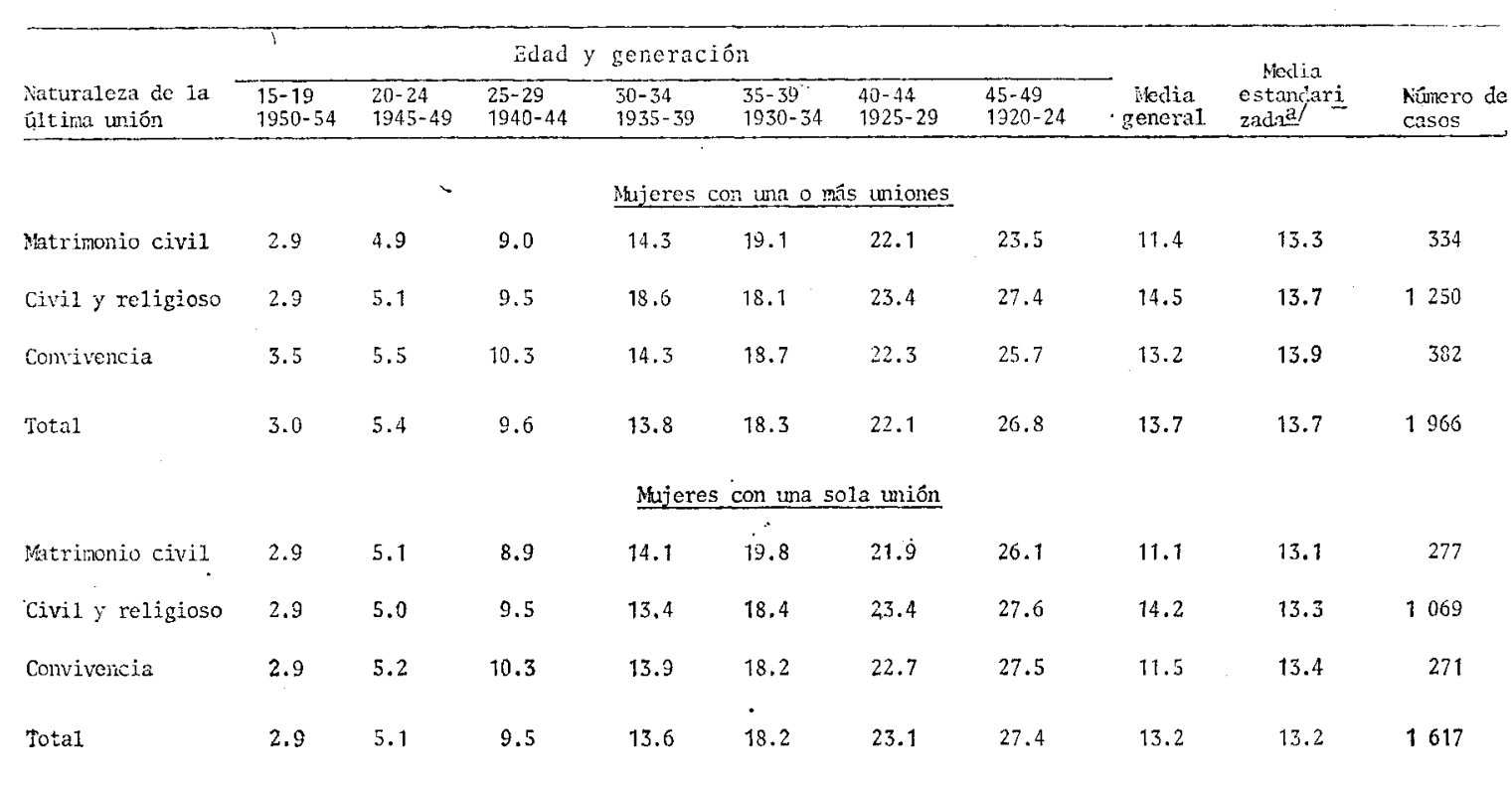

a La estandarización se hizo conforme a las estructuras por edad del conjunto de mujeres alguna vez unidas y con una sola unión. 
En el anexo $3^{19}$ aparecen las estructuras por edades para las mujeres actualmente unidas con una sola unión y para aquellas con una o más uniones. De la comparación resulta que la estructura correspondiente a las mujeres con una sola unión es ligeramente más joven que la estructura por edades de las mujeres con una o más uniones. Sin embargo, las diferencias más importantes que se observan son las que existen entre las estructuras por edades de las mujeres en matrimonio sólo civil y las otras dos categorías. Las mujeres en convivencia registran una estructura algo más joven que las mujeres en matrimonio civil y religioso pero no distan demasiado entre ellas. En cambio, la estructura de las mujeres en matrimonio sólo civil presenta proporciones por grupos de edad comparativamente más bajas en el grupo de edades de 30 a 34 años en adelante, con la consiguiente repercusión de ello sobre la duración media de uniones de la categoría.

En una misma generación, el tiempo medio pasado en unión (duración de unión) hasta una cierta edad por las mujeres que han contraído al menos una unión, depende de la edad a la cual contrajeron su primera unión. Si esta unión se encuentra disuelta, interviene el tiempo que ha transcurrido entre la separación, divorcio o viudez, a menos que se haya producido una nueva unión, caso en el cual lo que influye es el tamaño de intervalo entre uniones.

Respecto a la duración media calculada para diferentes generaciones en un momento dado, a las influencias ya mencionadas se agrega el efecto generacional. Vale decir que además de la edad al unirse, de las interrupciones de uniones y de las nuevas nupcias, la duración de uniones se ve afectada por los cambios que pueden sufrir las proporciones de uniones de una y otra naturaleza dentro de una misma generación o grupos de generaciones. Lo que le da especificidad a cada naturaleza de unión es justamente la manera diferente en que se produce su formación y disolución. Estas características son más difíciles de precisar porque el análisis no se efectúa dentro de generaciones ya que las variaciones que pueden sufrir los elementos específicos de cada naturaleza de unión pueden cambiar en las diferentes generaciones presentes en un momento dado.

De los datos del mismo cuadro 8 se desprende que las mujeres sobrevivientes al final de su vida reproductiva (mujeres de 45 a 49 años en la encuesta) llegan a acumular un tiempo medio de 26.8 años de unión. Esta media se eleva a 27.4 años en el caso de las mujeres con una sola unión ( $80.4 \%$ del total de mujeres alguna vez unidas).

Al diferenciar la edad a la primera unión por naturaleza de uniones, se observó que la convivencia se inicia en términos medios a los 17.4 años, el matrimonio sólo civil a los 18 años y el matrimonio civil y religioso a los 18.6 años. De acuerdo con esto, las mujeres convivientes deberían ser las que acumularan el número medio más elevado de años de unión

19 En el Anexo 3, cuadros 3 y 4 figuran las distribuciones por grupos de edades de las mujeres según naturaleza de la unión últina para mujeres con una sola unión y una o más uniones. 
al momento de la entrevista; sin embargo, no sucede así. En el cuadro 9 se aportan datos sobre la proporción de mujeres que se encuentran en uniones interrumpidas o que han contraído más de una unión según naturaleza de uniones. Según estos datos, la naturaleza de uniones que comporta la mayor proporción de mujeres con dos o más uniones es la convivencia. La pérdida de años de unión por estos conceptos se ve compensada, en este caso, por el número adicional de años pasados en unión por aquellas mujeres que contraen nuevas nupcias. Cuando esta compensación no se produce, como en el caso de las convivientes con una sola unión, la duración media de uniones es mucho menor.

\begin{tabular}{|c|c|c|c|}
\hline \multicolumn{4}{|c|}{$\begin{array}{l}\text { PROPORCIÓN DE MUJERES CON MÁS DE UNA UNIÓN Y CON UNIONES } \\
\text { INTERRUMPIDAS SEGÚN NATURALEZA DE SU UNIÓN ÚLTIMA } \\
(\text { Porcientos })^{\mathrm{a}}\end{array}$} \\
\hline $\begin{array}{l}\text { Naturaleza } \\
\text { de ia unión } \\
\text { ultima }\end{array}$ & $\begin{array}{l}\text { Mujeres con } \\
2 \text { o mas uniones }\end{array}$ & $\begin{array}{l}\text { Mujeres con uniones } \\
\text { interrusngidas }\end{array}$ & $\begin{array}{l}\text { Mujeres alguna } \\
\text { vez unidas }\end{array}$ \\
\hline $\begin{array}{l}\text { Matrimonio sólo } \\
\text { civil }\end{array}$ & $\begin{array}{l}18.1 \\
(68)\end{array}$ & $\left(\begin{array}{r}9.3 \\
(35)\end{array}\right.$ & $\begin{array}{r}100 \\
(375)\end{array}$ \\
\hline $\begin{array}{l}\text { Matrimonio civil } \\
y \text { religioso }\end{array}$ & $\begin{array}{l}15.3 \\
(206)\end{array}$ & $(8,0)$ & $\left(\begin{array}{rl}1 & \left.\begin{array}{r}100 \\
346\end{array}\right)\end{array}\right.$ \\
\hline Convivencia & $\begin{array}{r}31.7 \\
(154)\end{array}$ & $\begin{array}{l}18,0 \\
(87)\end{array}$ & $\begin{array}{r}100 \\
(486)\end{array}$ \\
\hline Total & $\begin{array}{r}19.4 \\
(428)\end{array}$ & $\begin{array}{r}9.2 \\
(203)^{2}\end{array}$ & $\left(\begin{array}{r}100 \\
2 \quad 207\end{array}\right)$ \\
\hline
\end{tabular}

- Las cifras entre paréntesis corresponden al número de casos.

El matrimonio sólo civil es el que registra la duración media más corta y no se observa compensación por nuevas nupcias como ocurre con la convivencia, así se trate de mujeres con una o más uniones. Tampoco posee da edad al contraer la primera unión más joven en comparación con las demás naturalezas de unión. Con estas características la media debería ser semejante a la de las mujeres en matrimonio civil y religioso y no tres años menos como se observa en términos medios. De aquí que se estime que el matrimonio sólo civil es un tipo de unión que ha venido aumentando entre las generaciones más jóvenes. Conforme a esto, la proporción de mujeres en los grupos de edades avanzadas es menor que en los otros tipos de unión y por esta misma razón el número medio total de años que han llegado a acumular a la fecha de la encuesta, es también comparativamente menor. 
Las mujeres en matrimonio civil y religioso, aun cuando contraen su primera unión a una edad más tardía, alcanzan las duraciones de uniones más prolongadas. La escasa diferencia de la duración media entre mujeres con una o más uniones y una sola unión, es reveladora de la poca influencia que tiene sobre este tipo de unión, la pérdida de años derivados de los intervalos entre uniones.

Los datos sobre proporciones de mujeres con uniones interrumpidas no fueron consideradas en los comentarios anteriores, en vista de que para el cálculo de la duración media de las uniones se eliminó este grupo. De cualquier forma, cabe mencionar la elevada proporción de mujeres con uniones disueltas que comporta la convivencia.

Del análisis de la duración media de las uniones, se desprende que las legales duran más que las convivencias y que al factor más importante de este diferencial es la estabilidad de la unión. Por lo tanto, no son las mujeres que se unen más jóvenes las que acumulan más años de unión. Así por ejemplo, las convivientes se unen en términos medios un año antes que las que contraen matrimonio civil y religioso y su duración de unión es un año más corta, también en términos medios.

\section{NuPCIALIDAD SEGÚN GRADOS DE URBANIZACIÓN Y REgIONES DEL PAÍS}

Como se mencionó antes, en la encuesta se distinguieron tres sectores al interior de la población que habitaba en localidades de menos de 20000 habitantes. Esta clasificación se hizo en atención al grado de urbanización de cada localidad y a la influencia que pudiera ejercer sobre ella la cercanía de un centro urbano cuando se trataba de localidades rurales (localidades de menos de 2500 habitantes).

De acuerdo con esto, las características de las mujeres entrevistadas se pueden analizar según pertenezcan a localidades semiurbanas (2 500 a 19999 habitantes), a localidades de menos de 2500 habitantes ubicadas en municipios donde existen núcleos urbanos o, a localidades también rurales pero que no se encuentran próximas de lugares urbanos ubicados en sus mismos municipios.

Del total de mujeres entrevistadas, el $54.5 \%$ habitaba en localidades rurales, el $13.3 \%$ en localidades rurales con influencia urbana y el $32.2 \%$ en núcleos semiurbanos. La distinción entre localidades rurales con y sin influencia urbana, pierde en parte su sentido al no haberse considerado en su definición la influencia que pudieran ejercer en núcleos urbanos próximos a la localidad de la entrevistada pero pertenecientes a un municipio diferente.

En cambio, las diferencias entre localidades rurales - con y sin influencia urbana-y las localidades semiurbanas pueden apreciarse de inmediato si se utiliza como ejemplo la proporción de analfabetas que existen en 
cada una de ellas. En la encuesta, $40.6 \%$ de las mujeres del sector rural y $30.2 \%$ del sector semiurbano pueden ser consideradas analfabetas ya que no terminaron ningún año de primaria. Los datos censales aportan evidencias en este mismo sentido. La proporción de población analfabeta mayor de 6 años era en 1970 de $41.1 \%$ en las localidades rurales, $24.9 \%$ en las localidades semiurbanas y $16 \%$ a nivel urbano. Estas mismas cifras censales, referidas sólo a las mujeres eran de $44.8 \%$ en el sector rural, $27.6 \%$ en el semiurbano y $17.8 \%$ en el urbano (20 000 habitantes y más). Como se puede ver, el diferencial opera en forma muy clara según el grado de urbanización y se agudiza cuando se hace además la distinción por sexo.

A la clasificación de la población por sectores según grados de urbanización, se podrían agregar otras clasificaciones que dieran cuenta más cabal de los complejos mecanismos que subyacen tras los indicadores demográficos que nos ocupan. En ocasiones las dificultades conceptuales de construir categorías más explicativas y otras veces la escasez de datos para hacerlo, limitan las relaciones que pueden establecerse entre los índices obtenidos y ofrecer por esta misma razón una descripción más profunda de los fenómenos que se estudian. En este sentido, la encuesta de Fecundidad Rural de México, a diferencia de las encuestas de este mismo tipo realizadas en Perú, Costa Rica y Colombia, abrió la posibilidad de efectuar análisis a nivel regional.

La regionalización del país efectuada conforma a criterios principalmente de índole geoeconómica, permite diferenciar los comportamientos demográficos a través del espacio. Espacio que puede ser jerarquizado en cuanto a sus distintos grados de desarrollo a partir de las características utilizadas en la definición de cada región.

Sin pretender el establecimiento de un vínculo explicativo directo entre los aspectos más globales que caracterizan a la población que habita una zona geográfica y la nupcialidad, ha parecido importante examinar si esta última adquiere diferentes modalidades según regiones del país.

La regionalización utilizada en la encuesta de México corresponde a la regionalización geoeconómica de Bassols modificada conforme a elementos estrictamente demográficos. ${ }^{20}$

En el mapa de México figura la distribución que se hizo del país en nueve regiones (véase el mapa 1). Las regiones, como se puede observar en el mapa, no corresponden estrictamente con las delimitaciones estatales. Hay zonas de algunos estados que figuran en una región y otras en otros.

A partir de un ordenamiento de los indicadores de índole socioeconómica que se calcularon en un trabajo especial dedicado a la regionalización

20 C. Welti, "Regionalización en la Encuesta de Fecundidad Rural de México", Mimeo. En este trabajo se detalla el procedimiento seguido para definir las regiones y se complementa con un análisis de indicadores sociales (alfabetismo, vivienda, drenaje y energía eléctrica) y económicos (distribución de la PEA por sectores económicos y por nivel de ingreso). 


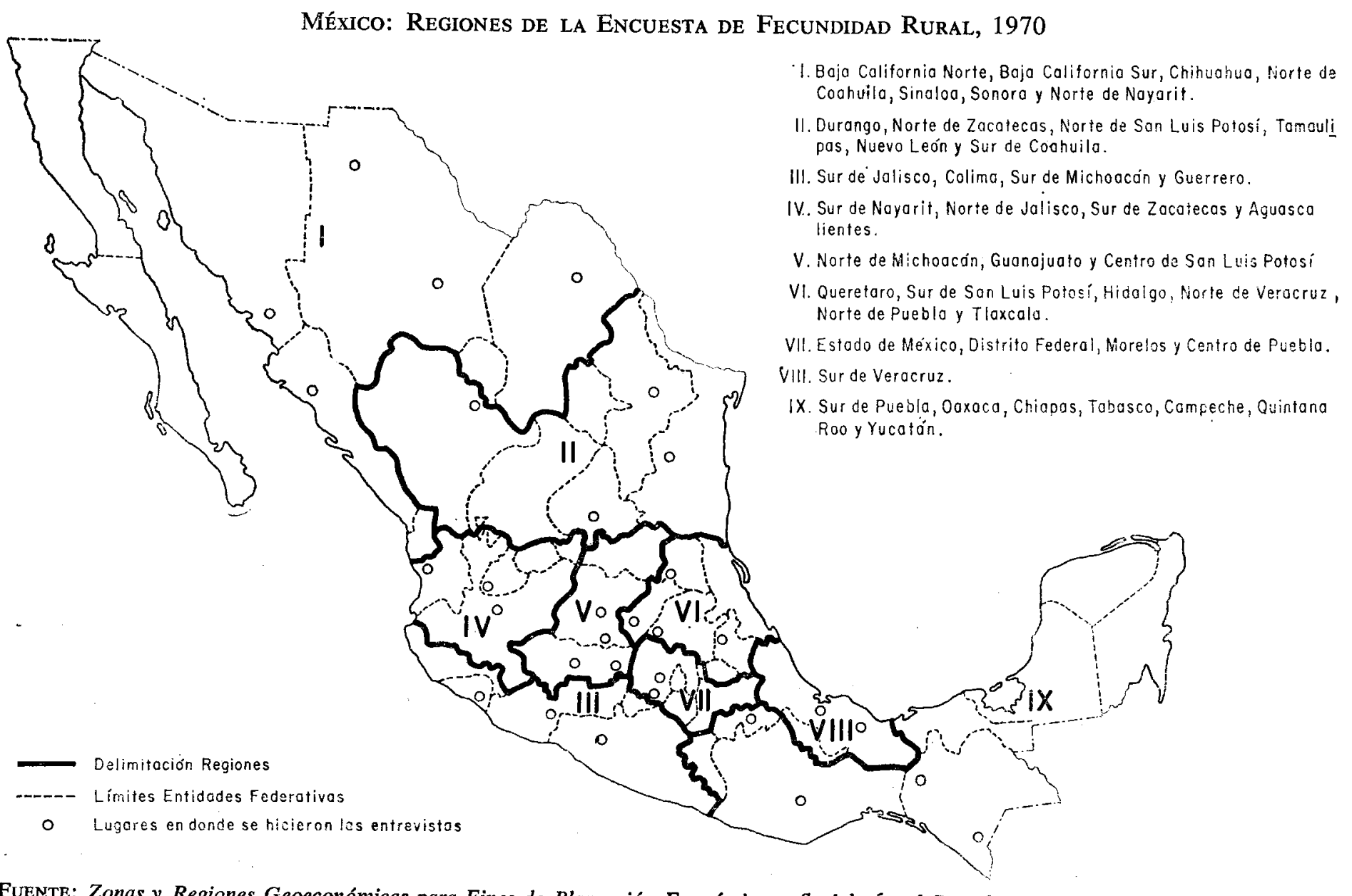

FUENTE: Zonas y Regiones Geoeconómicas para Fines de Planeación Económica y Social, Ángel Bassols Batalla, 1965. 
en esta encuesta, ${ }^{21}$ se efectuó una jerarquización de las regiones y su reagrupación en tres grandes categorías, ${ }^{22}$ como una manera de facilitar el análisis comparativo de la nupcialidad a través de ellas.

Las regiones incluidas en cada uno de dichos grandes grupos y sus principales características son en términos muy generales las siguientes:

$A$. Las regiones VII, I, II y IV, que corresponden a la zona norte del país, parte del Bajío y próxima al Distrito Federal, tienen la población más alfabetizada del país (más de un $80 \%$ de alfabetas), las mayores proporciones de viviendas con energía eléctrica y drenaje, la proporción más grande también de población económicamente activa (PEA) en el sector terciario, la población más numerosa con ingresos superiores a 1500 pesos (mensuales) y la más urbanizada. Cabe mencionar que la región VII que incluye al Distrito Federal, los estados de México, Morelos y Puebla, en cuanto a vivendas con drenaje y energía eléctrica y población en el sector terciario, registra niveles muy por encima de las otras tres regiones de este mismo grupo.

$B$. Las regiones viII y $\mathrm{v}$ que corresponden al sur de Veracruz y gran parte del Bajío (Guanajuato, norte de Michoacán y centro de San Luis Potosí) poseen características sociales, económicas y de urbanización que las sitúan en un nivel intermedio con respecto al resto de las regiones. Realizan un tipo de agricultura avanzada así como actividades ganaderas y poseen una de las más importantes zonas petroleras del país.

C. Las regiones que presentan los valores más bajos, en los indicadores seleccionados son la III, VI y IX, integradas por las entidades ubicadas en la banda costera occidental del país (entre Colima y Chiapas), los estados de Oaxaca, Tabasco, Campeche, la península de Yucatán, además de Querétaro y gran parte de la zona de la Huasteca. El centro de mayor desarrollo industrial existente en esta parte del territorio es el estado de Querétaro y, en menor grado, el estado de Tlaxcala. En estas regiones habitan los principales grupos indígenas del país.

En el anexo 4 se incluyen los valores de los indicadores socioeconómicos de cada región, así como el ordenamiento que se hizo de ellos. El simple ordenamiento en sentido creciente del lugar que ocupaba cada uno de los índices en cada una de las distintas regiones, resultó muy consistente. Los indicadores ocuparon dentro de una misma región casi siempre el mismo lugar.

Las características que se utilizaron para definir las regiones se refieren al conjunto de la población y no a la población de las localidades de menos de 20000 habitantes (rural y semiurbana) que está representada en la encuesta. Esto significa que los índices demográficos calculados para las distintas regiones pueden no ser del todo congruentes con los comportamientos esperados a partir de los niveles de desarrollo que posee la región en su conjunto. De cualquier forma, se estima que la región guarda un ma-

21 C. Welti, loc. cit.

22 Anexo 4. Ordenamiento de las regiones según los niveles de sus indicadores socioeconómicos. 
yor grado de homogeneidad que otras unidades de análisis, lo cual permite ubicar los fenómenos, en este caso la nupcialidad, en contextos más diferenciados.

En cuanto al inconveniente que puede representar la existencia de distintas estructuras por edades, por regiones y sectores, se comprobó estadísticamente que las diferencias entre ellas no eran significativas. ${ }^{23}$

\section{Características de la nupcialidad por sectores}

En la localidades rurales sin influencia urbana, el $75.5 \%$ de las mujeres está o ha estado unida. En las localidades con influencia urbana, esta proporción es del $74.3 \%$ y a nivel de localidades semiurbanas desciende a $70.2 \%$. Según estas cifras, la proporción de mujeres alguna vez unidas no difieren mucho entre sí, en especial aquellas referentes a los dos sectores rurales.

En los tres sectores la naturaleza de unión predominante es el matrimonio civil y religioso con poca variación en la proporción de un sector a otro (entre 61.5 y $58.4 \%$ ). El matrimonio sólo civil es más frecuente a nivel de las localidades rurales con influencia urbana, donde supera incluso la proporción de convivientes que por lo general es más elevada que la de matrimonios sólo civiles. La naturaleza de uniones que presenta mayores diferencias entre los tres sectores es la "sólo civil" que varía entre un $15.6 \%$ a nivel rural y un $22.1 \%$ a nivel de localidad rural con influencia urbana (véase el cuadro 10 ).

$\mathrm{Al}$ reunir los datos de los dos sectores rurales, se observa que para el sector rural en su conjunto, el matrimonio sólo civil representa el $16.8 \%$, el matrimonio civil y religioso el $60.9 \%$ y la convivencia el $22.7 \%$. Con esto, las diferencias entre sectores rurales y semiurbano se reducen a $0.4 \%$ más de matrimonios sólo civiles en el sector semiurbano y $0.8 \%$ más de convivencia en el sector rural. Como las proporciones de matrimonios civiles y religiosos son idénticas en ambos sectores, resulta que a nivel rural la proporción de convivencia es algo más elevada que la que prevalece a nivel semiurbano.

La edad media al contraer la primera unión, es la misma a nivel de los dos sectores rurales, es decir, rural con y sin influencia urbana; en ambos sectores esta edad es de 18 años para el conjunto de mujeres de 15 a 49 años y, 18.8 y 18.7 años, en el caso de aquellas mujeres cuyas edades superaban los 35 años de edad en el momento de la entrevista.

En cambio, en el sector semiurbano la primera unión se celebra 0.7 años más tarde. Esta diferencia de casi medio año marca una tendencia, orientada en el sentido de que a mayor grado de urbanización la edad al unirse sería más tardía. La edad media de 21.4 años para el conjunto de mujeres del país ${ }^{24}$ corroboraría de manera indirecta esta tendencia, ya

23 No significativos al $95 \%$ según prueba de hipótesis realizada con la $x^{2}$.

24 J. Quilodrán, "Tablas de nupcialidad..." 
QUILODRĀN: NUPCIALIDAD RURAL

Cuadro 10

MUJERES ALGUNA VEZ UNIDAS SEGÚN NATURALEZA DE SU ÚLTIMA UNIÓN Y EDAD A LA PRIMERA UNIÓN POR SECTORES

(para 100 mujeres en cada sector)

\begin{tabular}{|c|c|c|c|c|c|c|c|c|}
\hline & \multicolumn{2}{|c|}{ Sector rural } & \multicolumn{2}{|c|}{$\begin{array}{c}\text { Rural con } \\
\text { influencia urbang }\end{array}$} & \multicolumn{2}{|c|}{$\begin{array}{c}\text { Sector } \\
\text { semi-urbano }\end{array}$} & \multicolumn{2}{|c|}{ Tota1 } \\
\hline & Nímero & $\frac{\mathfrak{B}}{\mathrm{i}}$ & Nímero & 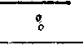 & Nínero & $\div$ & Número & $:$ \\
\hline \multicolumn{9}{|l|}{$\begin{array}{l}\text { Naturaleza de ia } \\
\text { Gitima unión }\end{array}$} \\
\hline $\begin{array}{l}\text { Matrinonio sólo } \\
\text { civil }\end{array}$ & 191 & 15.6 & 66 & 22.1 & 118 & 17.2 & 375 & 16.9 \\
\hline $\begin{array}{l}\text { Matrimonio civil } \\
y \text { religioso }\end{array}$ & 755 & 61.5 & 174 & 58.4 & 418 & 60.9 & 1347 & 60.9 \\
\hline Convivencia & 282 & .22 .3 & 58 & 19.5 & 150 & 21.9 & 490 & 22.2 \\
\hline Tota1 & 228 & 55.5 & 298 & 13.5 & 686 & 31.0 & 2212 & 100.0 \\
\hline \multicolumn{9}{|l|}{$\begin{array}{l}\text { Ldad a la } \\
\text { primera tuiónin }\end{array}$} \\
\hline 15 a 49 años & 1216 & 13.0 & 294 & 18.0 & 681 & 18.7 & 2191 & 18.2 \\
\hline 35 a 39 años & .461 & 18.8 & 114 & 18.7 & 288 & 19.5 & 863 & 19.0. \\
\hline
\end{tabular}

que esta media no podría darse si la edad al unirse no fuera bastante más tardía entre las mujeres pertenecientes a localidades urbanas.

En resumen, se puede decir que a nivel de sectores la población presenta características muy homogéneas con respecto al tipo o naturaleza de unión que contrae, ya que las proporciones de mujeres unidas en matrimonio sólo civil, civil y religioso y en convivencia no varían de manera fundamental de un sector a otro. En el caso de la edad a la primera unión, las diferencias entre sectores tampoco son definitivas, aunque se advierta un retraso de más de medio año en la edad media a la primera unión del sector semiurbano con respecto a la del rural.

2. Características de la nupcialidad por regiones

a) Naturaleza de las uniones

Existen fuertes diferencias en cuanto a las proporciones de mujeres alguna vez unidas que habitan en las localidades de menos de 20000 habitantes en cada una de las regiones del país (véanse el cuadro 11 y el mapa 1).

Las regiones que se destacan con una elevada proporción de mujeres alguna vez unidas son las viII y vi con un $80.7 \%$ y $79.9 \%$, respectiva- 
mente. Estas regiones comprenden parte de la zona centro del país, la Huasteca y el norte y sur de Veracruz. En el otro extremo, se ubica la Región IV con un $62.7 \%$; esta región está conformada por ei estado de Aguascalientes, parte sur del estado de Nayarit, norte de Jalisco y sur de Zacatecas. En el resto de las regiones, estas proporciones fluctúan entre 70 y $77 \%$.

Disparidades aun más grandes que las que se acaban de mencionar se dan entre naturalezas de uniones de una región a otra. Hasta aquí se había

Cuadro 11

MuJeres alguna VEZ UNIDAS SEGÚN NATURALEZA DE SU UNIÓN Última POR REGIONES

(para 100 mujeres en cada región)

\begin{tabular}{|c|c|c|c|c|c|c|c|c|c|c|}
\hline \multirow{2}{*}{$\begin{array}{l}\text { Saturaleza de la } \\
\text { útima wión }\end{array}$} & \multicolumn{10}{|c|}{ Regiones } \\
\hline & i & II & III & IV & V & VI & VII & VIII & IX & Total \\
\hline $\begin{array}{l}\text { Matrimonio sỏlo } \\
\text { civil }\end{array}$ & $\begin{array}{l}36.0 \\
(62)\end{array}$ & $\begin{array}{l}17.2 \\
(47)\end{array}$ & $\begin{array}{l}10.8 \\
(20)\end{array}$ & $\begin{array}{l}3.1 \\
(6)\end{array}$ & $\begin{array}{l}2.8 \\
(9)\end{array}$ & $\begin{array}{l}10.2 \\
(27)\end{array}$ & $\begin{array}{l}15.3 \\
(61)\end{array}$ & $\begin{array}{l}26.3 \\
(47)\end{array}$ & $\begin{array}{l}44.6 \\
(96)\end{array}$ & $\begin{array}{r}17.0 \\
(375)\end{array}$ \\
\hline $\begin{array}{l}\text { Matrinonio civil } \\
\text { y religioso }\end{array}$ & $\begin{array}{l}39.5 \\
(68)\end{array}$ & $\begin{array}{r}66.0 \\
(18 i)\end{array}$ & $\begin{array}{r}62.4 \\
(116)\end{array}$ & $\begin{array}{r}90.7 \\
(175)\end{array}$ & $\begin{array}{r}92.0 \\
(301)\end{array}$ & $\begin{array}{r}63.1 \\
(168)\end{array}$ & $\begin{array}{r}58.4 \\
(234)\end{array}$ & $\begin{array}{l}28.5 \\
(51)\end{array}$ & $\begin{array}{l}24.7 \\
(53)\end{array}$ & $\begin{array}{r}60.8 \\
(1347)\end{array}$ \\
\hline Convivientes & $\begin{array}{l}24.5 \\
(42)\end{array}$ & $\begin{array}{l}16.8 \\
(46)\end{array}$ & $\begin{array}{l}26.8 \\
(50)\end{array}$ & $\begin{array}{r}6.2 \\
(12)\end{array}$ & $\begin{array}{l}5.2 \\
(17)\end{array}$ & $\begin{array}{l}26.7 \\
(71)\end{array}$ & $\begin{array}{l}26.3 \\
(105)\end{array}$ & $\begin{array}{l}45.3 \\
(81)\end{array}$ & $\begin{array}{l}30.7 \\
(66)\end{array}$ & $\begin{array}{l}22.2 \\
(490)\end{array}$ \\
\hline Total & $\begin{array}{l}100.0 \\
(172)\end{array}$ & $\begin{array}{l}100.0 \\
(274)\end{array}$ & $\begin{array}{l}100.0 \\
(186)\end{array}$ & $\begin{array}{l}100.0 \\
(193)\end{array}$ & $\begin{array}{l}100.0 \\
(327)\end{array}$ & $\begin{array}{l}100.0 \\
(266)\end{array}$ & $\begin{array}{l}100.0 \\
(400)\end{array}$ & $\begin{array}{l}100.0 \\
(179)\end{array}$ & $\begin{array}{l}100.0 \\
(215)\end{array}$ & $\begin{array}{l}100.0 \\
(2212)\end{array}$ \\
\hline $\begin{array}{l}\text { Mujeres alguna vez } \\
\text { unidas/total entre } \\
\text { vistadas (8) }\end{array}$ & 70.2 & 77.8 & 77.2 & 62.5 & 71.4 & 79.9 & 74.8 & 80.7 & 72.4 & 73.7 \\
\hline
\end{tabular}

dicho que la unión predominante era siempre el matrimonio civil y religioso; sin embargo, esta afirmación válida para el país en su conjunto, no lo es a nivel de algunas regiones. Los datos del cuadro 11 muestran que este tipo de unión está por debajo del $30 \%$ en las regiones viII y Ix, es decir, en la franja sur y sureste del país. La situación inversa se presenta en la zona centro y del Bajío (regiones $\mathrm{v}$ y IV) donde el matrimonio civil y religioso es casi la única forma de unión.

Las diferencias son también notables en lo que respecta a los matrimonios sólo civiles y las convivencias. Además, una proporción relativamente reducida de mujeres en matrimonio civil y religioso puede adquirir distinto significado según resulte de una abundancia de uniones consensuales o de matrimonios sólo civiles. Así, por ejemplo, en la región viII la convivencia es el tipo de unión más frecuente $(45.3 \%)$ mientras en la región 
IX es el matrimonio civil el que predomina ( $44 \%$ ), aun cuando en ambas regiones la convivencia $(45.3$ y $30.7 \%$ ) supera al matrimonio civil y religioso.

En siete de las nueve regiones (de la I a la vin) la proporción de mujeres en matrimonio civil y religioso es más elevada que en las otras categorías. Esta preponderancia no significa de ninguna manera uniformidad ya que la proporción correspondiente a las regiones IV y $\mathrm{v}$ son más de dos veces mayores que la correspondiente a la región I que es la que presenta la proporción más reducida $(39.5 \%)$,

En seis de las nueve regiones la convivencia es más frecuente que la unión sólo civil, y en siete, menor que la civil y religiosa. Las regiones que se escapan a esta tendencia son las regiones viII y IX (mencionadas antes) y la I y II. En la región $\mathrm{x}$ la unión sólo civil supera a la civil y religiosa y a la convivencia. En las regiones I y II el matrimonio sólo civil es más abundante que la convivencia pero menos frecuente que el matrimonio civil y religioso.

Lo que se ha querido destacar es el hecho de que las uniones legales (sólo civil y religiosa) aunque representen en todas las regiones más del $50 \%$ de las mujeres alguna vez unidas, se componen internamente de diferente manera. Casi siempre prevalece la civil y religiosa sobre la sólo civil pero resultaría interesante profundizar sobre esta última ya que el 45\% de las mujeres de una de las regiones más deprimidas del país como es la región $\mathrm{xX}$ y el $36 \%$ de aquellas pertenecientes a la región $\mathrm{r}$, que se considera de las más desarrolladas, se encuentran casadas en este tipo de unión. ¿Significa lo mismo el matrimonio sólo civil en ambas regiones? ¿Es acaso producto de legalizaciones de uniones que se inician como convivencias y que después del matrimonio sólo civil recurren todavía a la sanción religiosa? Estas preguntas llevan a considerar la necesidad de analizar las transformaciones de los estados civiles que puede llegar a experimentar una misma pareja. Esta dinámica puede presentar diferentes modalidades, ocurrir a ritmos distintos en cada región y, como consecuencia, producir las distintas distribuciones por estados civiles que se han analizado aquí para un momento dado, el de la encuesta.

b) Edad media a la primera unión

La primera constatación que surge de comparar las edades promedios a la primera unión entre regiones (véase el cuadro 12) son las diferencias que se detectan. La gama de edades fluctúa entre 17.2 años en la parte sur de Veracruz (región viII) y 19.4 años en la región IV (Aguascalientes y parte de los estados de Jalisco, Nayarit y Zacatecas). En la primera región, la naturaleza de unión predominante es la convivencia, con un $45.3 \%$ acompañada de proporciones de uniones sólo civiles, y civiles y religiosas que casi no difieren entre sí; en la segunda (región Iv), el $90.7 \%$ de la población unida se declara en matrimonio civil y religioso.

Entre estos extremos, las diferencias entre las medias observadas son 
Cuadro 12

EdAD MEdia a la PRIMERa UNIÓN PARA EL CONJUNTO DE MUJERES ALGUNA VEZ UNIDAS, POR REGIÓN

\begin{tabular}{rc} 
Regiones & $\begin{array}{c}\text { Edad a la } \\
\text { primera unión } \\
\text { (años) }\end{array}$ \\
\hline I & 18.7 \\
II & 18.6 \\
III & 17.4 \\
IV & 19.4 \\
V & 18.6 \\
VI & 17.8 \\
VII & 18.0 \\
VIII & 17.2 \\
IX & 18.4 \\
Total & 18.2 \\
\hline
\end{tabular}

más pequeñas. Cabría distinguir las regiones con edades medias inferiores a. 18 años, de aquéllas con medias entre 18 y 19 años y 19 más. La distribución por regiones es como se indica a continuación:

a) Regiones VIII, III y VI con edades medias inferiores a 18 años (17.2, 17.4 y 17.8 años respectivamente). Estas regiones abarcan la franja costera suroccidental (costa del Pacífico), todo Veracruz (zona del Golfo) y parte de algunos estados del centro incluidas las Huastecas;

b) Regiones VII, IX, II, V y I con edades medias al unirse entre 18.0 y 18.7 años. Este grupo de regiones cubre geográficamente la mayor parte del territorio y reúne las características socioeconómicas más diversas. Se tiene a la región vil que comprende las zonas rurales y semiurbanas del Distrito Federal y estados vecinos, cuyos indicadores socioeconómicos presentan los valores más altos de todo el país. Contrastando con esta región se encuentra la región IX que vendría a ser la región de menor desarrollo relativo dentro del conjunto. Sin embargo, la edad media en la región vil es menor que en la región $\mathrm{xx}$, cuando cabría esperar que en esta última la edad media fuera más temprana por la fuerte proporción de mujeres en matrimonio sólo civil, que como ya se vio se unen a una edad, por lo general más joven que las mujeres en matrimonio civil y religioso;

c) Región IV con 19.4 años de edad media al unirse. Se destaca por sobre el resto de las regiones del país. Aunque pertenece al grupo de regiones que presentan mayor grado de desarrollo, es superada en este aspecto por las regiones I, II y VII, por lo cual este factor no parece ser el determinante de la edad más tardía al unirse.

Las distribuciones regionales según naturaleza de unión y edades medias al unirse, dan cuenta de pautas diferenciales de nupcialidad en cuyo estudio habrá que ahondar. La dinámica de la formación, transformación e in- 
terrupción de uniones no queda aclarada en un análisis con las limitaciones del que aquí se presenta. No sólo se requiere ahondar en estos procesos desde el punto de vista demográfico sino también sobre aquellos aspectos de índole psicosocial involucradas en la dicisión de contraer o interrumpir una unión.

La imposibilidad de establecer una relación directa entre los aspectos de la nupcialidad vistos aquí y las regiones con todos los aspectos socioeconómicos involucrados en su definición, resulta evidente. Esto no significa negar las interrelaciones existentes entre los aspectos estructurales y demográficos, sólo tiene por objeto enfatizar la necesidad de afinar tanto las definiciones de las categorías de referencia macroestructurales como el manejo de la información relativa a fenómenos demográficos, de modo de posibilitar el establecimiento de los nexos que permitan zanjar la brecha que existe entre ambos niveles. Parte de la falta de concordancia que aquí se observa puede derivarse de que la relación se ha tratado de establecer entre las características de las regiones y de la nupcialidad, las primeras caracterizadas por indicadores para el conjunto de población rural y urbana, y las segundas referidas sólo a aquellas mujeres pertenecientes a los sectores rurales y semiurbano de cada una de estas regiones.

\section{La NUPCIALIDAd EN FUnCIÓN DE ALGUNAS CARACTERÍSTICAS SOCIOECONÓMICAS DE LAS ENTREVISTADAS}

Las características de la nupcialidad retenidas para efectuar este análisis son las mismas ya utilizadas antes. La naturaleza de la unión y la edad al contraer la primera unión, son examinadas aquí a la luz del nivel educacional alcanzado por la mujer, del hecho que ésta ejerza o no una actividad remunerada, y del tipo de ocupación del cónyuge.

Tanto las características educacionales como ocupacionales de las mujeres entrevistadas en esta encuesta, han sido objeto de estudios pormenorizados, ${ }^{25}$ de modo que aquí se retoman sólo algunos datos muy generales sobre estos aspectos haciendo hincapié en las características de la nupcialidad ya mencionadas.

Del total de mujeres que han contraído al menos una unión, el $38.1 \%$ no completó ningún año de primaria y el $91 \%$ no concluyó el ciclo de educación primaria. Esta situación cambiaría en la medida que las generaciones más jóvenes presenten niveles de escolaridad más elevados. ${ }^{26}$

En lo que atañe a la ocupación de la mujer, el $80.8 \%$ de ellas declara no desempeñar ninguna actividad por la cual perciba una remuneración. Esta proporción se eleva al $83.7 \%$ en el caso de mujeres alguna vez uni-

25 C. Gougain, "Escolaridad y fecundidad", Encuesta de Fecundidad Rural de México (Mimeo.) y C. Welti, "Ocupación y fecundidad", Encuesta de Fecundidad Rural de México (Mimeo.).

${ }_{26} \mathrm{C}$. Gougain, loc. cit. 
das, lo cual denota un diferencial entre las proporciones de mujeres solteras y unidas; en efecto, un $28 \%$ de solteras se declara ocupado frente a un $16.3 \%$ de mujeres casadas, convivientes, separadas o viudas. Aunque el análisis de este capítulo se refiere a las mujeres alguna vez unidas, es importante resaltar que el cambio de estado civil, en este caso el ingreso de mujeres solteras a la vida matrimonial, retiraría parte de ellas de la población económicamente activa.

Esta última afirmación que parte de datos globales puede no ser cierta a niveles más desagregados, como por ejemplo, de las regiones o incluso de las generaciones, ya que las más jóvenes pueden estar participando más en el mercado de trabajo. También hay que advertir que la disminución del grupo de mujeres que ejercen una actividad remunerada no necesariamente debe coincidir con el cambio de estado civil; éste pudiera estar más ligado a la llegada de un primer hijo que a la celebración de la unión. Sin embargo, cualquiera de estos puntos requiere de una profundización que rebasa el objetivo de este trabajo, pero que no por ello se consideran menos importantes de investigar.

En forma adicional a la actividad ocupacional de la mujer, la encuesta contiene, para las mujeres con uniones actuales, información sobre la ocupación del padre de la entrevistada, sobre la ocupación de su suegro y sobre la ocupación de su cónyuge al iniciarse la unión y en el momento de la entrevista. Cada una de estas distribuciones se presentan tan concentradas en las categorías "agrícola de bajo nivel" y "ni tradicionales ni agrícolas" que un análisis rápido de ellas muestra que no ofrece diferencia analizar la nupcialidad en función de una u otra. Consideradas de manera conjunta, las categorías ocupacionales antes mencionadas, se tiene que el 91.6\% de los padres de las entrevistadas y el $\mathbf{9 5 . 2 \%}$ de los suegros de las mismas se ubican en ellas. En cuanto a la actividad ocupacional del cónyuge, al unirse con la entrevistada, $64 \%$ desempeñaba ocupaciones agrícolas de bajo nivel y $29.4 \%$ ocupaciones del tipo "ni tradicionales ni agrícolas" que incluye, principalmente a "obreros calificados" (18.7\%). Estas proporciones no habían variado de manera fundamental al momento de celebrarse la entrevista: la proporción de cónyuges en actividades agrícolas de bajo nivel, descendió un $6 \%$ en beneficio de la categoría "obreros no agrícolas" (obreros calificados y no calificados) que aumentó a su vez en un $5 \% .27$

Estas cifras muestran de manera elocuente la homogeneidad de esta población en lo que se refiere al tipo de actividad económica que realiza. La gran mayoría de los cónyuges ocupa posiciones de bajo nivel en la agricultura y sólo un poco mejores cuando trabajan en el sector no agrícola (obreros calificados). Al comparar la generación de los padres con la de la mujer entrevistada y su cónyuge, el cambio que se advierte es que la presencia de estos últimos en ocupaciones agrícolas de bajo nivel es menor

27 Marginales Comparativos de las Encuestas PECFAL-R, variables Núms, 69, 78, 84 y 86 , CELADE, Santiago de Chile, 1973. 
(10\%) que la de sus suegros. Es decir, se observa un ligero desplazamiento hacia ocupaciones diferentes de las agrícolas de hombres cuyas edades deben fluctuar entre los 20 y 50 años y más (cónyuges de las mujeres entrevistadas).

\section{La nupcialidad según nivel educacional}

La distribución de las mujeres según la naturaleza de la unión en que se encuentran y el nivel educacional alcanzado, refleja de inmediato diferenciales importantes entre mujeres casadas legalmente (en matrimonio sólo civil y civil y religioso) y unidas en convivencia.

A pesar de que el conjunto de la población entrevistada presenta niveles muy bajos de escolaridad (véase el cuadro 13) —casi el $40 \%$ de las mujeres alguna vez unidas no terminaron ningún año de primaria y $91 \%$ no completó el ciclo - se advierten diferencias muy claras según la naturaleza de la unión. La diferencia más importante entre las convivientes y las mujeres en unión legal reside en que estas últimas cursan más años de primaria aun cuando no la completen. Las proporciones de mujeres con uniones legales y primaria completa duplican en tamaño a las correspondientes a las mujeres en convivencia con este mismo nivel educacional.

\section{Cuadro 13}

MUjeres alguna VEZ UNIDAS SEgún NATURALEZA DE LA Última UNIÓN Y EDAD MEDIA A LA PRIMERA UNIÓN SEGÚN NIVEL EDUCACTONAL

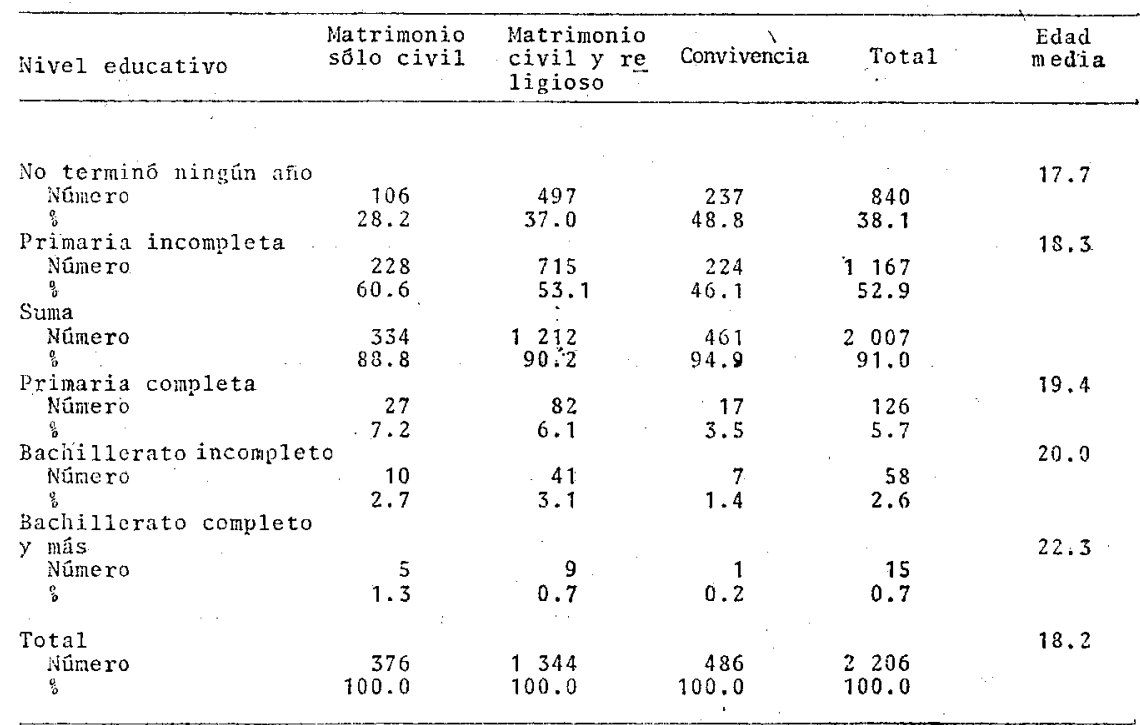


Apenas el 2.6\% del total de mujeres llega a cursar estudios de secundaria (bachillerato) y la proporción de aquéllas que completa este nivel o lo supera, no alcanza el $1 \%(0.7 \%)$.

La edad a la primera unión según el nivel educacional fluctúa entre 17.7 años y 22.3 años y se eleva de manera sistemática al aumentar los años de escolaridad. Si el nivel educacional fuera el único determinante de la edad al casarse, un aumento en el número medio de años de escolaridad de la mujer rural y semiurbana en México debería verse acompañado por un retardo en la edad media al contraer la primera unión.

En el supuesto de que se diera un aumento paulatino del nivel educacional que hiciera que aquellas mujeres que en la actualidad no completan ni siquiera un año de primaria lo completaran y así sucesivamente, uniéndose a las edades que corresponden en la encuesta a cada uno de tales niveles, la edad media al unirse se elevaría, en el medio rural, de 18.2 a 19.2 años. $^{28}$

El nivel más bajo de escolaridad observado corresponde a las mujeres de convivencia, las cuales como se vio antes son las que se unen a edades más jóvenes. De manera inversa, las mujeres en uniones legales presentan niveles más elevados de escolaridad y en términos medios se unen más tarde. El nivel ligeramente mayor de escolaridad que poseen las mujeres en matrimonio sólo civil puede ser atribuido a que se han beneficiado proporcionalmente más con el aumento que se ha venido dando en los niveles de escolaridad por tener una estructura por edades más joven. ${ }^{29}$

A partir de estos datos cabría esperar que en las regiones del país donde el número medio de años de escolaridad de las mujeres es más elevado, ${ }^{30}$ la edad a la primera unión también lo sea.

En el cuadro 14 se comparan datos relativos al nivel educativo de las entrevistadas, calculado a través del número medio de años de escolaridad por región, con la información sobre edad media al contraer la primera unión en cada una de ellas. Como indicador representativo de la naturaleza de unión se escogió la proporción de mujeres en convivencia por estimarse como más sensible ya que presenta variaciones importantes entre regiones.

La primera observación que surge de la comparación es que en las regiones IV y VIII, se verifica que a mayor escolaridad, corresponde una edad más elevada a la primera unión.

Las mujeres de la región viII registran el número de años de escolaridad más bajo, la edad más temprana a la unión y la proporción más grande de convivientes. Por su parte, la región IV reúne uno de los niveles medios de escolaridad más elevados (2.9 años, mientras el más alto corresponde a

28 Edad a la primera unión para las mujeres que cursen algunos años de primaria: 18.3 años; 19.4 años para aquellas que completen los estudios de primaria; 20 años para las que asistan a bachillerato o secundaria; y 22.3 años para las que por lo menos terminen este último ciclo.

29 C. Gougain, loc. cit., cuadro 4.

so C. Gougain, loc, cit., cuadro 3. 
Cuadro 14

INDICADORES DE EDUCACIÓN Y NUPCIALIDAD ENTRE REGIONES

\begin{tabular}{|c|c|c|c|c|c|c|c|c|c|c|}
\hline Indicadores & $\mathrm{I}$ & II & III & IV & $v$ & $V \mathrm{~T}$ & VII & VIII & $I X$ & Total \\
\hline $\begin{array}{l}\text { Escolaridad } \\
\text { inedia (años) }\end{array}$ & 3.0 & 2.6 & 1.6 & 2.9 & 1.8 & 2.1 & 2.2 & 1.4 & 1.7 & 2.1 \\
\hline $\begin{array}{l}\text { Edad media a la } \\
\text { primera unión }\end{array}$ & 18.7 & 18.6 & 17.4 & 19.4 & 18.6 & 17.8 & 18.0 & 17.2 & 15.4 & 18.2 \\
\hline Conviviertes ( $(\%)$ & 24.5 & 16.8 & 26.8 & $6.2^{\circ}$ & 5.2 & 26.7 & 26.3 & 45.3 & 30.7 & 22.2 \\
\hline
\end{tabular}

Fuentes: Escolaridad: C. Gougain, "Escolaridad y fecundidad", Mimeo, cuadro 3;

Edad media a la primera unión: cuadro 12 de este artículo; Convivientes: cuadro 11 de este artículo.

la región I con tres años), una edad media a la primera unión muy por encima del resto de las regiones y una de las dos proporciones más reducidas de mujeres en convivencia.

De modo que no es ni la región más deprimida del país ni la más desarrollada, según los indicadores para el conjunto de las regiones, las que presentan las situaciones extremas en cuanto a educación y características de la nupcialidad.

De cualquier forma, las regiones VIII y IV presentan pautas de nupcialidad bien diferenciadas. En el sur de Veracruz (región viII) la unión se inicia muy temprano, a una edad media de 17.2 años, y escasamente el $28 \%$ declara encontrarse o haber contraído alguna vez matrimonio civil y religioso; predomina la unión consensual y el matrimonio sólo civil es frecuente. En la parte centro occidental del país (región Iv) la unión se celebra en términos medios dos años después que en la región anterior y el matrimonio civil y religioso es la naturaleza de unión dominante.

Las pautas de nupcialidad descritas para la región sur de Veracruz pueden hacerse extensivas a las regiones III y vi; vale decir, norte de Veracruz, parte de los estados de Querétaro, San Luis Potosí, Hidalgo, norte de Puebla y Tlaxcala, además de los estados de Guerrero, Colima y parte occidental de Jalisco y Michoacán (véase el mapa 1).

La situación en las regiones I y II se asemeja más a la norma de nupcialidad descrita para la región iv, con la variante de una proporción de convivientes más elevada y una edad a la unión casi un año menor.

La región $\mathrm{v}$ es la más atípica de todas las regiones. Su nivel de escolaridad es de los más bajos; sin embargo, en ella la edad media a la primera unión se sitúa por encima de la media para localidades de menos de 20000 habitantes y la proporción de convivientes es aún más baja que en la región Iv. De la misma manera que en la región IX, aquí no se estaría dando la relación esperada entre educación y edad a la unión. En estas regiones la edad al contraer la primera unión es incluso mayor que en la región viI cuya escolaridad media es superior (2.2 años). 
Las observaciones anteriores indican que además de la educación existen otros factores que intervienen en forma decisiva en la configuración de las pautas de nupcialidad. ${ }^{31}$ Entre los factores que pudieran estar influyendo ha parecido importante aludir, aunque sea en forma muy superficial, al papel de la iglesia. La formación y desenvolvimiento de la familia constituye una de las principales preocupaciones de esta institución; de aquí que no sea extraño que ejerza presiones para mantener vigentes las normas que la regulan. Una de estas normas sería la sanción del vínculo matrimonial por parte de ella. De este modo, la naturaleza de unión aparece ligada a una mayor o menor observancia de las reglas establecidas por la iglesia.

Sin pretender que la proporción de católicos que se obtiene de la pregunta censal sobre religión constituya un buen estimador de religiosidad, se le ha utilizado aquí para verificar si la proporción de mujeres que se declaran en uniones civiles y religiosas (categoría que incluye las en matrimonio sólo por la iglesia) se incrementa con la proporción de mujeres que se declaran católicas en el censo.

Si se toman como referencia las dos regiones que pueden ser consideradas como extremas, es decir las regiones IV y viII, se encuentra que existen efectivamente diferencias en cuanto a las proporciones de católicas. Estas diferencias no pueden ser muy amplias en una población que casi en su totalidad (96\%) se declara católica; sin embargo, siguen la relación esperada. En los estados de Aguascalientes, Jalisco y Zacatecas, que conforman grosso modo la región IV, las proporciones son de 99.1, 98.5 y 98.3\% respectivamente. En el estado de Veracruz (región VIII y parte de la región vi) la proporción desciende a $94.6 \%$. La situación en la región IX varía ya que las proporciones oscilan entre $87.2 \%$ en Tabasco (proporción más baja de todo el país), y $97 \%$ en Oaxaca.

Las entidades de la región I y II (todo el norte del país) presentan proporciones de mujeres católicas por lo general algo superiores a $95 \%$. O sea, la norma estaría en este sentido más cercana a la del centro del país, pero las proporciones de mujeres unidas en convivencia son muy superiores a las de las regiones $\mathrm{N}$ y $\mathrm{v}$, al igual que la frecuencia del matrimonio sólo civil.

31 Se calcularon los índices de masculinidad por regiones a partir de datos censales para ver si no había detrás de las diferentes edades al unirse un problema de desequilibrio entre los sexos debido a la migración. Según los datos que figuran en el Anexo 5 las regiones con índices de masculinidad más bajos a nivel rural son la III y la IX. Sin embargo, en la región III la edad a la primera unión se celebra muy temprano (17.4 años), mientras en la región $\mathbf{~ X}$ esta edad es ligeramente superior a la media total (18.4 años). En la región VII, que tiene índices muy bajos desde el grupo de 15 a 19 años, la edad a la unión es también baja; en cambio la región IV, con índices por encima del de otras regiones, registra una edad mucho más tardía al unirse. Como se trata de índices para las edades más jóvenes, cabe siempre la posibilidad de cambios generacionales que puedan alterar estas conclusiones pero es difícil ya que es en estos grupos de edades donde se concentra gran parte de la población analizada en la encuesta. En resumen, no se observa que la edad a la primera unión se retrase por efecto de un desnivel entre los efectivos de ambos sexos. 
La relación más clara entre edad al casarse y proporción de mujeres que se declaran católicas, se daría en las regiones cuyas entidades superan prácticamente el $98 \%$ de mujeres que se declaran católicas. Como ya fue mencionado, la relación entre "proporción de católicas" y características de la nupcialidad estaría dándose a través de la naturaleza de la unión. La iglesia presionaría para que la unión que se contrae sea de tipo legal. Las exigencias de índole social e incluso económicas que implica el matrimonio civil y religioso, influirían en el hecho de que se celebre a edades más tardías que la convivencia y que el matrimonio sólo civil.

En resumen, la educación no se presenta como el único factor que estaría determinando niveles de edad al casarse relativamente elevados. $\mathrm{La}$ asociación entre un mayor nivel educacional y una edad más tardía a la unión se observa, pero para que su influencia se haga manifiesta a nivel del conjunto de la población ésta debe acceder a una educación equivalente a ciclo primario. Lo que se ha tratado de señalar al introducir como explicativa la variable "proporción de católicos" es que existen otras instituciones, diferentes de la educacional, cuya influencia puede estar en algunos casos actuando en el mismo sentido que ésta en cuanto a retardar la edad a la primera unión.

\section{La nupcialidad según tipo de ocupación}

a) Naturaleza de la unión y edad media a la primera unión según ocupación de la mujer.

Del total de mujeres alguna vez unidas, un $16.3 \%$ lleva a cabo una actividad remunerada casi siempre por dinero (véase el cuadro 15), la proporción de mujeres que declara trabajar por remuneración en especie es ínfimo.

El principal diferencial según ocupación surge entre las mujeres con uniones subsistentes y uniones interrumpidas. La proporción de activas entre estas últimas es muy superior a la de aquellas que se declaran unidas al momento de la entrevista ( 12 y $43 \%$ respectivamente). La gran mayoría de las mujeres que trabajan son separadas o divorciadas.

Es probable que la separación, por ocurrir a edades más tempranas que la viudez, deje a la mujer con un número de hijos dependientes más elevado; estos hijos, por su corta edad no están todavía en condiciones de aportar ayuda económica al hogar, con la consiguiente obligación de la madre de buscar un trabajo remunerado para mantenerlos. La viuda en cambio tiene mayores probabilidades de recibir ayuda económica de sus hijos, lo cual aunado a su edad más avanzada determinaría su menor participación en una actividad remunerada.

Entre las mujeres con uniones actuales o subsistentes, la que menos participa es la unida en matrimonio sólo civil $(9.4 \%)$. Como la mayoría de las mujeres de esta categoría se concentra en edades muy jóvenes (menos de 30 años) sus hijos deben ser todos pequeños. Este hecho podría explicar por qué trabajan con menos frecuencia que las mujeres unidas en 


\section{Cuadro 15}

MuJeres alguna Vez UNIDAS SEgún NATURALEzA DE SU Última UNIÓN, EDAD MEDIA A LA PRIMERA UNIÓN Y OCUPACIÓN

(para 100 mujeres en cada naturaleza de unión)

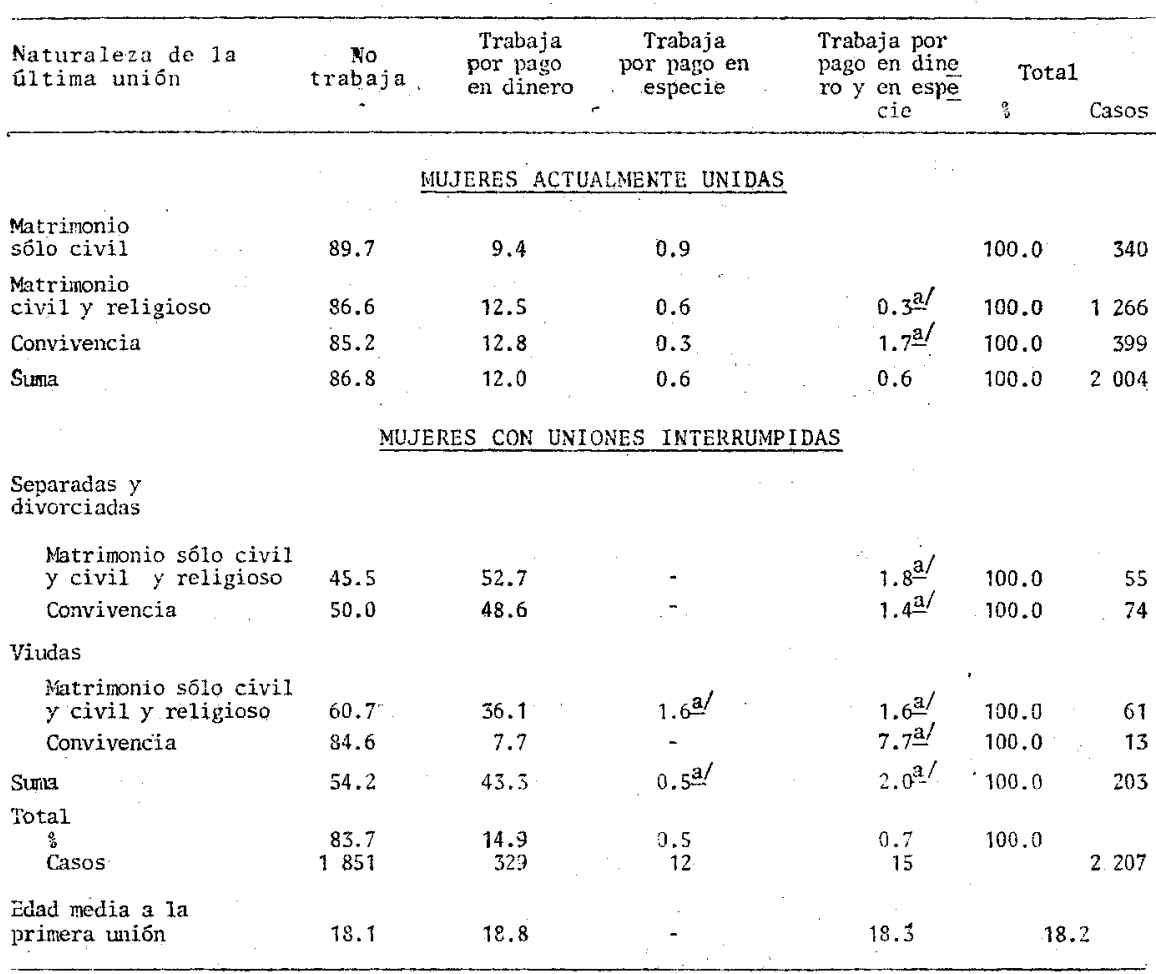

a Número no suficiente de casos.

convivencia y en matrimonio civil y religioso ( 12.5 y $12.8 \%$, respectivamente). El número insuficiente de casos manejados no permite concluir si entre las mujeres con uniones interrumpidas se observan diferencias según naturaleza de la unión.

En el caso de las edades al contraer la primera unión, los diferenciales resultan en el sentido de que las mujeres que trabajan se unen a edades medias más tardías que las que no trabajan. La diferencia entre ambas edades es de 0.7 años.

b) Naturaleza de la unión según ocupación del cónyuge

El dato sobre ocupación del cónyuge sólo se obtuvo en la encuesta para las mujeres con uniones subsistentes. En el cuadro 16 se presenta este 
dato reagrupado en cinco categorías ocupacionales y clasificado según naturaleza de la unión.

Lo más relevante que se obtiene de esta distribución es, en primer lugar, la concentración de los cónyuges de las entrevistadas en las categorías ocupacionales "agrícola de nivel bajo" y "ni tradicionales ni agrícolas" (92.5\% del total). En segundo lugar, está el hecho de que la concentración en las ocupaciones agrícolas de bajo nivel es mayor entre los cónyuges de las convivientes. La proporción es entre 10 y $12 \%$ más elevada según se compare con aquellas mujeres casadas en matrimonio sólo civil o con aquellas que lo están en matrimonio civil y religioso.

\section{Cuadro 16}

MUJERES ACTUALMENTE UNIDAS SEGÚN OCUPACIÓN DEL CÓNYUGE Y NATURALEZA DE LA ÚLTIMA UNIÓN

\begin{tabular}{|c|c|c|c|c|c|c|c|c|}
\hline \multirow{2}{*}{$\begin{array}{l}\text { Ocupación } \\
\text { del cónyuge }\end{array}$} & \multicolumn{2}{|c|}{$\begin{array}{l}\text { Matrimonio } \\
\text { sólo civil }\end{array}$} & \multicolumn{2}{|c|}{$\begin{array}{c}\text { Matrinonio } \\
\text { civil y religioso } \\
\end{array}$} & \multicolumn{2}{|c|}{ Convivencia } & \multicolumn{2}{|c|}{ Total } \\
\hline & Número & g & Nimero & 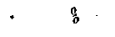 & Nứnero & $\stackrel{\circ}{\mathfrak{O}}$ & Núnero & : \\
\hline Tradicional & 0 & 0.0 & 22 & 1.7 & 7 & 1.7 & 29 & 1.4 \\
\hline $\begin{array}{l}\text { Agricola de } \\
\text { - nivel alto }\end{array}$ & 3 & 0.9 & 7 & 0.6 & 1 & 0.3 & 11 & 0.6 \\
\hline $\begin{array}{l}\text { Agricola de } \\
\text { uivel medio }\end{array}$ & 12 & 3.5 & 30 & 2.4 & 16 & 4.0 & 48 & 2.9 \\
\hline $\begin{array}{l}\text { Arricola de } \\
\text { nivel bajo }\end{array}$ & 189 & 55.6 & 730 & 57.6 & 272 & 67.5 & 1191 & 59.2 \\
\hline $\begin{array}{l}\text { Ni tradicio } \\
\text { nal ni agrî } \\
\text { cola }\end{array}$ & 123 & 37.9 & 451 & 35.6 & 88 & 21.8 & 668 & 33.3 \\
\hline Indefinida & 7 & 2.1 & 26 & 2.1 & 19 & 4.7 & 52 & 2.6 \\
\hline Total & 340 & 100.0 & 1266 & 100.0 & 403 & 100.0 & 2009 & 100.0 \\
\hline
\end{tabular}

a Comprende no respuesta, no sabe o no trabaja.

En el cuadro 16 se incluyó la alternativa "no se sabe, no responde, no trabaja" por tratarse de que era la mujer quien respondía sobre la ocupación del cónyuge y esto podría acarrear a su vez diferenciales según la naturaleza de la unión. La proporción de mujeres en esta situación resultó ser pequeña dentro del conjunto $(2.6 \%)$, pero efectivamente se presentó diferenciada según las mujeres estuvieran en unión legal o en convivencia. Entre estas últimas, el nivel de no respuesta es del doble del de las otras categorías de unión. El número de casos impide determinar si la mayor frecuencia que se observa entre las convivientes es atribuible al hecho de que una proporción más grande de los cónyuges de estas mujeres no trabajaba al momento de la entrevista (edad avanzada, desempleo), o, si se 
debe a que tienen un menor conocimiento del tipo de ocupación que desempeñan.

\section{NÚMERO MEDIO DE HIJOS NACIDOS VIVOS SEGÚN NATURALEZA DE UNIÓN, POR REGIONES}

Por hipótesis se postulaba que las diferentes naturalezas de uniones exponían en forma diferencial a la mujer al riesgo de concebir. Es decir, que en ausencia de un control deliberado de la fecundidad, la naturaleza de la unión con mayor duración media de tiempo debería ser la que reuniera al mayor número de hijos.

Para el conjunto de la población alguna vez unida (véase el cuadro 17), el número medio de hijos nacidos vivos es de 5.3, igual al que alcanza la población unida al momento de la entrevista. Las mujeres en uniones interrumpidas tienen un número medio de 5 hijos y el de las mujeres que se declaran solteras es mínimo ( 0.1 hijos).

Las mujeres actualmente unidas en matrimonio civil y religioso son las que alcanzan el mayor tiempo medio de duración de uniones y el número más elevado de hijos nacidos vivos (14.5 años y 5.7 hijos). Por su parte,

\section{Cuadro 17}

NÚMERO MEDIO DE HIJOS NACIDOS VIVOS SEGÚN ESTADO CIVIL Y REGIONES

\begin{tabular}{|c|c|c|c|c|c|c|c|c|c|c|}
\hline \multirow{2}{*}{ Estado civil } & \multicolumn{9}{|c|}{ Regiones } & \multirow{2}{*}{ Media total } \\
\hline & I & II & III & IV & $v$ & $V \mathrm{I}$ & VII & VIII & $I X$ & \\
\hline Actuahnente unidas & 5.5 & 5.4 & 5.2 & 5.8 & 5.7 & 5.4 & 5.3 & 4.0 & 4.9 & 5.3 \\
\hline $\begin{array}{l}\text { Matrimonio sólo } \\
\text { civil }\end{array}$ & 5.1 & 4.2 & 3.6 & a & 5.3 & 5.3 & 3.9 & 3.5 & 4.7 & 4.4 \\
\hline $\begin{array}{l}\text { Matrinonio civil } \\
\text { y religioso }\end{array}$ & 6.2 & 5.8 & 5.5 & 6.0 & 5.7 & 5.8 & 5.6 & 4.2 & 5.0 & 5.7 \\
\hline Convivientes & 4.8 & 5.0 & 5.1 & a $/$ & $\underline{a} /$ & 4.4 & 5.7 & 4.2 & 5.1 & 4.9 \\
\hline $\begin{array}{l}\text { Uniones interrum } \\
\text { pidas } \\
\text { ( } v \text { iudas, separa- } \\
\text { das y divoreia- } \\
\text { das) }\end{array}$ & 4.7 & 5.5 & 5.3 & 5.1 & 5.6 & 6.0 & 4.7 & 4.4 & 4.1 & 5.0 \\
\hline $\begin{array}{l}\text { AJguya ves uni- } \\
\text { dasb }\end{array}$ & 5.4 & 5.4 & 5.2 & 5.8 & 5.6 & 5.4 & 5.2 & 4.0 & 4.8 & 5.3 \\
\hline Solteras & 0.1 & 0.1 & 0.0 & 0.2 & 0.0 & 0.1 & 0.1 & 0.0 & 0.1 & 0.1 \\
\hline
\end{tabular}

a Número insuficiente de casos.

b El número medio de hijos nacidos vivos de las mujeres alguna vez unidas según naturaleza de unión fue: Matrimonio sólo civil 4.3, matrimonio civil y religioso $5.5, \mathrm{y}$ convivientes 4.8 . 
las convivientes llegan a tener un número medio de hijos nacidos vivos de 4.9; vale decir que una diferencia de sólo 1.3 años en la duración total de uniones con respecto al matrimonio civil y religioso redunda en 0.8 hijos menos en término medio. En cuanto a las mujeres en matrimonio sólo civil, su número medio de hijos nacidos vivos (4.4 hijos) es más acorde con la duración de unión más breve que presenta esta categoría de matrimonio (11.4 años).

$\mathrm{Al}$ analizar las características de la nupcialidad según naturaleza de las uniones, se observó que la convivencia era la más inestable porque presentaba la mayor proporción de mujeres con uniones disueltas y con dos 0 más uniones. Las disoluciones, cuando no se prolongan en otra unión y los lapsos que median entre una y otra unión (cuando hay más de una), acortan la duración total de las uniones y contrarrestan así, como en el caso de la convivencia, el efecto de una edad más joven a la unión. Estas interrupciones se traducen, en términos de la fecundidad alcanzada, en un número medio más bajo de hijos nacidos vivos.

Si se calcula el número medio de hijos por año de unión para cada naturaleza de unión, ${ }^{32}$ resulta que el número anual de hijos que "produce" el matrimonio civil y religioso y sólo civil es semejante $(0.395$ y 0.393 , respectivamente). En cambio, la convivencia, alcanza una cifra algo menor (0.371). Cabe preguntarse pues si la convivencia no comporta en realidad más interrupciones que las que son observables a través de la información disponible, por ejemplo, las que pudieran derivarse de separaciones de hecho por migraciones temporales del cónyuge. Otra alternativa, que no excluye la anterior, es que las interrupciones entre uniones se den entre las convivientes en edades de alta fertilidad haciendo disminuir el número medio de hijos más rápidamente que cuando la interrupción ocurre a edades más tardías y por lo mismo; de menor fertilidad.

De cualquier forma, habría que analizar más a fondo el significado que tiene el valor más bajo de este índice entre las convivientes. $i$ Trasluce simplemente los efectos de una mejor o menor declaración del número de hijos nacidos vivos? ¿Responde, como se adelantó, a una menor exposición al riesgo de concebir que la que se puede deducir de la información proporcionada por las mujeres? o bien, iposeen estas mujeres, cuyas características personales las definen como las de menor educación y cuyos cónyuges ocupan las posiciones más bajas de la escala ocupacional, efectivamente una menor fertilidad?

Como se puede apreciar, la influencia de la nupcialidad sobre la fecundidad puede darse de diferentes maneras. Las combinaciones posibles entre edad a la primera unión e interrupciones de uniones según naturaleza

32 El número medio de hijos nacidos vivos con respecto a la duración media de uniones proporciona una estimación de la "productividad" de hijos por años de unión en cada naturaleza de unión. Aquí se ha dividido la media general de duración de uniones de las mujeres actualmente unidas ( $C f$. el cuadro 8) correspondiente a cada naturaleza de uniones por el número medio de hijos nacidos vivos respectivo $(C f$. el cuadro 16). 
de las uniones son muchas. La duración distinta de exposición al riesgo de concebir de la mujer, que define cada una de estas combinaciones, acarrea a su vez diferencias en los números medios de hijos nacidos vivos. Un retardo en la edad a la primera unión no debe interpretarse automáticamente como una pérdida de años de unión, ya que éste puede verse compensado por una disminución de las mujeres con uniones interrumpidas antes de finalizar su periodo reproductivo. Tampoco debe considerarse como definitivo el número medio de hijos alcanzados por mujeres con uniones disueltas, sobre todo cuando son producto de separaciones, debido a que la propensión a contraer nuevas nupcias entre estas mujeres prolonga su exposición al riesgo de concebir.

Del total de hijos nacidos vivos de las mujeres unidas al momento de la encuesta, las mujeres en matrimonio civil y religioso $(60.9 \%)$ son madres del $65.4 \%$; aquellas en matrimonio sólo civil (17\%) del $13.7 \%$; y las convivientes $(22.2 \%)$ del $20.2 \%$. Esto significa que las modificaciones que tendrían más impacto sobre los niveles de la fecundidad serían aquelias ligadas al comportamiento de las mujeres en matrimonio civil y religioso, ya sea que cambien sus pautas de nupcialidad o adopten métodos dirigidos a controlar su fecundidad. Pueden darse, desde luego, ambos tipos de modificaciones simultáneamente.

Si las mujeres convivientes llegaran a tener el número medio de hijos nacidos vivos observados entre las mujeres en matrimonio civil y religioso (5.7), y la aportación proporcional de hijos correspondiente a cada naturaleza de unión se mantuviera igual, el número medio para el conjunto de mujeres de 15 a 49 años pasaría de 5.3 a 5.7 hijos. Si por el contrario, vía el aumento en la edad a la primera unión o en la proporción de mujeres con uniones interrumpidas, las mujeres en matrimonio civil y religioso tuvieran el número debido de los hijos que tienen los convivientes (4.9 hijos), el número medio de hijos del grupo de mujeres actualmente unidas no sería de 5.3 hijos sino de 4.8 hijos; es decir, medio hijo menos.

Ahora, en lo que respecta a la fecundidad por regiones, las diferencias en el número medio de hijos nacidos vivos son acentuadas. Para mu-

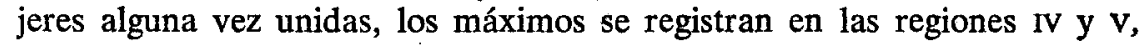
con un número medio 5.8 y 5.6 , respectivamente. Estas mismas regiones son las que presentan las mayores frecuencias de mujeres en matrimonios civiles y religiosos que como ya se vio, es la naturaleza de la unión que expone más prolongadamente a la mujer el riesgo de concebir.

Las regiones I, II, VI, III y VII, registran un número medio de hijos muy similar, entre 5.4 y 5.2 hijos. Sin embargo, sus características son muy variadas no sólo con respecto a la nupcialidad sino también en relación a los aspectos socioeconómicos. Así por ejemplo, la edad media a la primera unión es de 17.4 años en la región III y 18.7 años en la región r, la proporción de convivientes de 26.8 y 24.5 , respectivamente (muy similar) y el grado de desarrollo entre ambas muy diferente, ocupan casi las posiciones extremas. 
Los números medios más bajos de hijos nacidos vivos por regiones corresponden a la vir y Ix (4.0 y 4.8 hijos). Conforme a los indicadores utilizados para estudiar el grado de desarrollo de las regiones, debe concluirse que es en las regiones más deprimidas, las más pobres, donde las mujeres tienen el número medio de hijos más bajo. Este hallazgo es congruente con el hecho de que se trata de las regiones que presentan las proporciones más elevadas de mujeres en convivencia, cuyas pautas de nupcialidad, como ya se ha expresado, conducen a un menor número de años de exposición de las mujeres al riesgo de concebir. Otro factor, que posiblemente también influye sobre los resultados medios registrados en estas regiones, es el de una mayor omisión en la declaración de los hijos nacidos vivos ligado con toda certeza a una menor sobrevivencia de éstos.

Las diferencias en el número medio de hijos por naturaleza de la unión al interior de las regiones, no sigue siempre rigurosamente la tendencia de que el número medio de hijos nacidos vivos de las mujeres en uniones civiles y religiosas superan siempre aquellas de las mujeres en convivencias (V.gr. las regiones VII y IX). Aquí el número de casos podría estar introduciendo diferencias aleatorias que aconsejan no fundar conclusiones a este nivel de desglose de la información.

Aun cuando en el futuro la planeación familiar constituya un elemento fundamental en la determinación de los niveles de la fecundidad, habrá que tener en cuenta que en forma previa a su adopción por parte de la población, estos niveles no eran uniformes a través de todo el país. La interpretación del éxito de los programas de planeación familiar, en especial a nivel regional, tendrá que considerar la importancia que revisten las "variables intermedias" ${ }^{\prime 3}$ que rigen la formación y disolución de las uniones en edad fértil, es decir, de aquellas variables que en este trabajo se han reunido bajo la denominación de "pautas de nupcialidad".

\section{RESUMEN Y CONCLUSIONES}

En México alrededor de una tercera parte de la población de mujeres en edades reproductivas se encuentra soltera. A mayor grado de urbanización corresponde una proporción también mayor de mujeres en este estado civil. Las dos terceras partes de las mujeres alguna vez unidas se encuentran unidas legalmente en matrimonio civil o civil y religioso. El grupo de mujeres con uniones disueltas (más o menos $5 \%$ ) se compone principalmente de viudas $(2.5 \%)$ y separadas $(2.1 \%)$; las divorciadas sólo representan el $0.6 \%$.

Las mujeres de las áreas rurales y semiurbanas que han tenido al menos una unión hasta el momento de la encuesta superan a la proporción censal

${ }^{33}$ Esquema de las variables intermedias de la fecundidad en Freedman, Davis y Blake, Los factores sociológicos de la fecundidad, México, CELADE, El Colegio de México, 1967. 
para el conjunto del país. En estas áreas la convivencia es más abundante que a niveles más urbanos como también lo es la frecuencia de mujeres con uniones interrumpidas o disueltas, en su gran mayoría, provenientes de convivencias.

La norma de la nupcialidad general puede caracterizarse por una entrada a la unión a edad temprana (18 años) a través de la celebración de una unión la mayoría de las veces legal. Esta unión en el $80 \%$ de los casos constituye la única que la mujer llega a contraer durante su vida reproductiva (antes de los 50 años) y permanece en ella alrededor de 27 años. La estabilidad que presentan las uniones conduce en una población como ésta, que no controla de manera efectiva su fecundidad, a descendencias finales del orden de 8 hijos, y un número medio de 5 para el conjunto de mujeres de 15 a 49 años. No se observan diferencias generacionales en las distribuciones por edad al contraer la primera unión que apunta hacia un ascenso de la edad media al contraer esta primera unión.

Cuando se procede a diferenciar la edad a la primera unión, el número de uniones, y la proporción de mujeres con uniones disueltas según la naturaleza de la unión en que se encuentra la mujer, surgen pautas de nupcialidad diferentes para el matrimonio sólo civil, civil y religioso y para la convivencia. Esta última es la unión que se inicia a edades más jóvenes (a una edad media de 17.4 años y modal 15 años) se disuelve con más frecuencia, casi siempre por separación de hecho, y tiene la proporción más elevada de mujeres con más de una unión. Las segundas nupcias operan en el caso de la convivencia como factor compensatorio del elevado nivel de disolución de uniones que en ellas se da, con lo cual se prolonga de este modo, su duración media.

El matrimonio sólo civil parece constituir un tipo de unión de expansión relativamente reciente que se sitúa, en cuanto a edad a la primera unión (18 años), entre la convivencia y el matrimonio civil y religioso. Su situación es también intermedia, entre estos dos tipos de uniones, en lo que respecta a la proporción de uniones disueltas pero se diferencia de la convivencia en que la propensión de las mujeres a contraer segundas nupcias es menor.

La norma de las uniones más estable es, sin lugar a dudas, la de los matrimonios civiles y religiosos. Estos registran el mayor número de mujeres con una sola unión, la proporción más baja de mujeres con uniones interrumpidas y, por lógica, la proporción también más reducida de mujeres con dos o más uniones. Es la naturaleza de las uniones que se unen en términos medios más tarde (edad media a la primera unión de 18.5 años y modal de 17 años) y que sin embargo alcanza la duración más prolongada.

Desde el punto de vista de la nupcialidad, la única diferencia de importancia que se advierte entre el nivel rural y semiurbano es en la edad a la primera unión. A nivel rural la media de edad es de 18 años y en las localidades semiurbanas de 18.7 años. 
La edad a la primera unión y la naturaleza de las uniones, que fueron las dos características de la nupcialidad utilizadas en el análisis por regiones, muestran diferencias fundamentales de una región a otra. Puede decirse que en México coexisten varias pautas de nupcialidad y que a nivel de localidades de menos de 20000 habitantes pueden distinguirse al menos dos en forma clara: 1) unión temprana, alrededor de los 17 años y fuerte proporción de mujeres en convivencia. Esta pauta corresponde al estado de Veracruz, zona de la Huasteca y en cierta medida también a la costa sur del Pacífico; 2) unión relativamente tardía y con una escasa proporción de mujeres en convivencia, (zona centro y centro occidental, comprendido el Bajío).

El resto del país presenta edades medias a la unión que fluctúan entre 18 y 18.7 años y proporciones de mujeres en convivencia de alrededor del $25 \%$. Esta aparente homogeneidad en cuanto a nupcialidad se ve desvirtuada a nivel de grados de desarrollo entre las regiones que encierra este grupo.

El análisis regional aporta sin duda conocimientos sobre los diferenciales geográficos de la nupcialidad pero no se observa una relación sistemática entre grado de desarrollo de las regiones y pautas de nupcialidad. Tampoco se da este tipo de relación cuando se considera el número medio de años de escolaridad de las entrevistadas en cada región y las características de la nupcialidad de las mismas.

Estas constataciones de ninguna manera pretenden negar que los factores socioeconómicos, entre ellos la educación, juegan un papel importante en la determinación de las pautas de nupcialidad. Lo que resulta evidente es que las vinculaciones entre los fenómenos demográficos y aspectos estructurales son más complejas y, que hay factores tales como la educación que requieren traspasar un cierto umbral, que la población en su conjunto adquiere un cierto número de años de escolaridad para que su influencia se torne significativa (mínimo más de 3 años de primaria).

La ocupación de la mujer y del esposo sirvió para informarnos sobre el estado civil de la mujer que ejerce una actividad remunerada. A nivel rural y semiurbano, se confirma el hecho de que las mujeres que participan con mayor frecuencia en la actividad económica son las solteras y las mujeres con uniones disueltas.

En lo que se refiere al conocimiento de la nupcialidad a nivel rural y semiurbano uno de los hallazgos más importantes que se desprende de este trabajo es la influencia que ejerce la estabilidad de la unión en la determinación de los niveles de la fecundidad. Así, se tiene que no es la naturaleza de unión cuyas mujeres se unen más jóvenes la que alcanza los números medios de hijos nacidos más elevados. La proporción de mujeres con uniones disueltas y los intervalos entre uniones intervienen de manera decisiva en la determinación del tiempo de exposición de la mujer al riesgo de concebir. Este hecho no descarta la importancia que posee la edad a la primera unión; más bien la complementa en lo que se refiere a la influencia que ambas tienen sobre la duración de las uniones. 
Cuando se relaciona la fecundidad de las entrevistadas con las características de la nupcialidad, la relación entre número de hijos nacidos vivos y naturaleza de la unión se da en el sentido esperado. Es decir, la naturaleza de unión que expone durante más tiempo a la mujer al riesgo de concebir es la que reúne el número más elevado de hijos. Así, se tiene que la naturaleza de unión más estable, la civil y religiosa, alcanza el mayor número medio de hijos (5.7) y la convivencia, un número más reducido (4.9 hijos). Por lo que se refiere a las regiones, en las que predomina la convivencia el número medio de hijos nacidos vivos es menor que en aquellas en que la naturaleza de unión más frecuente es la civil y religiosa.

Las características de la nupcialidad asociadas a cada una de las naturalezas de unión (legales y consensuales) permiten concluir que éstas representan un buen punto de partida para un análisis de índole más cualitativa sobre la formación y disolución de las parejas. Aquí se vio que las mujeres que se unían en convivencia tenían niveles medios más bajos de educación, de modo que estudios centrados sobre las características socioeconómicas de quienes contraen uno u otro tipo de unión, podrían aportar conocimientos más profundos sobre las estrategias de reproducción que adoptan diferentes grupos sociales.

\section{ANEXO 1}

Las mujeres solteras de 15 a 49 años $\left(S_{15-49}\right)$ de las localidades de menos de 20000 habitantes fueron estimadas de la siguiente forma:

$$
S_{15-49}=S_{12 \text { y más }}-\left(S_{12-14}+S_{50 \text { y más }}\right)
$$

El censo de 1970 proporcionó información sólo para el total de la población de 12 años y más por estado civil y tamaño de localidad. Esto obligó a estimar la población soltera en localidades de 20000 habitantes de 12 a 14 años $\left(S_{12.14}\right)$ y de 50 y más años $\left(S_{50 \text { y más }}\right)$, lo cual se hizo bajo los siguientes supuestos:

a) Que la población soltera entre 12 y 14 años representa a nivel de este tamaño de localidad una proporción igual a la nacional (32.7\%).

b) Que la población soltera de 50 años y más representa también la misma proporción a nivel de localidades de menos de 20000 habitantes y a nivel nacional $(4.5 \%)$.

De acuerdo al número de solteras de 12 años y más (3 209 313) existentes en las localidades de menos de 20000 habitantes y conforme al primer supuesto, el número de mujeres de 12 a 14 años sería 1049445 (3 209313 x 0.327); y el número de mujeres de 50 años y más según el supuesto $b$ ) sería de 144419 (3209313 x 0.045). El número de mujeres en estos grupos de edad es entonces de 1193864.

El número de solteras de 15 a 49 años en las localidades de menos de 20000 habitantes resulta entonces de 2015449 (3 209313 - 1193864 ) y 
la proporción respecto de la población total de 15 a 49 años en dichas localidades es de $30.57 \%$ (2 015 449/6 590792 ).

Esta proporción de 30.6 sobrestima la proporción de solteras a nivel rural y semiurbano en la medida de que en estas localidades el número de mujeres que contrae unión entre 12 y 14 años es mayor que a nivel nacional. Una mortalidad más elevada en estas localidades sería también motivo de sobrestimación.

\section{ANEXO 2}

INDICES DE MASCULINIDAD POR TAMAÑo DE LOCALIDAD

(MÉXICo, 1970)

Antes de comparar los datos contenidos en el cuadro 2 del trabajo, se calcularon los índices de masculinidad por tamaño de localidad. Esto tiene

\section{Gráfica 3}

INDICES DE MASCULINIDAD POR TAMAÑOS DE LOCALIDAD Población de 10 años y más

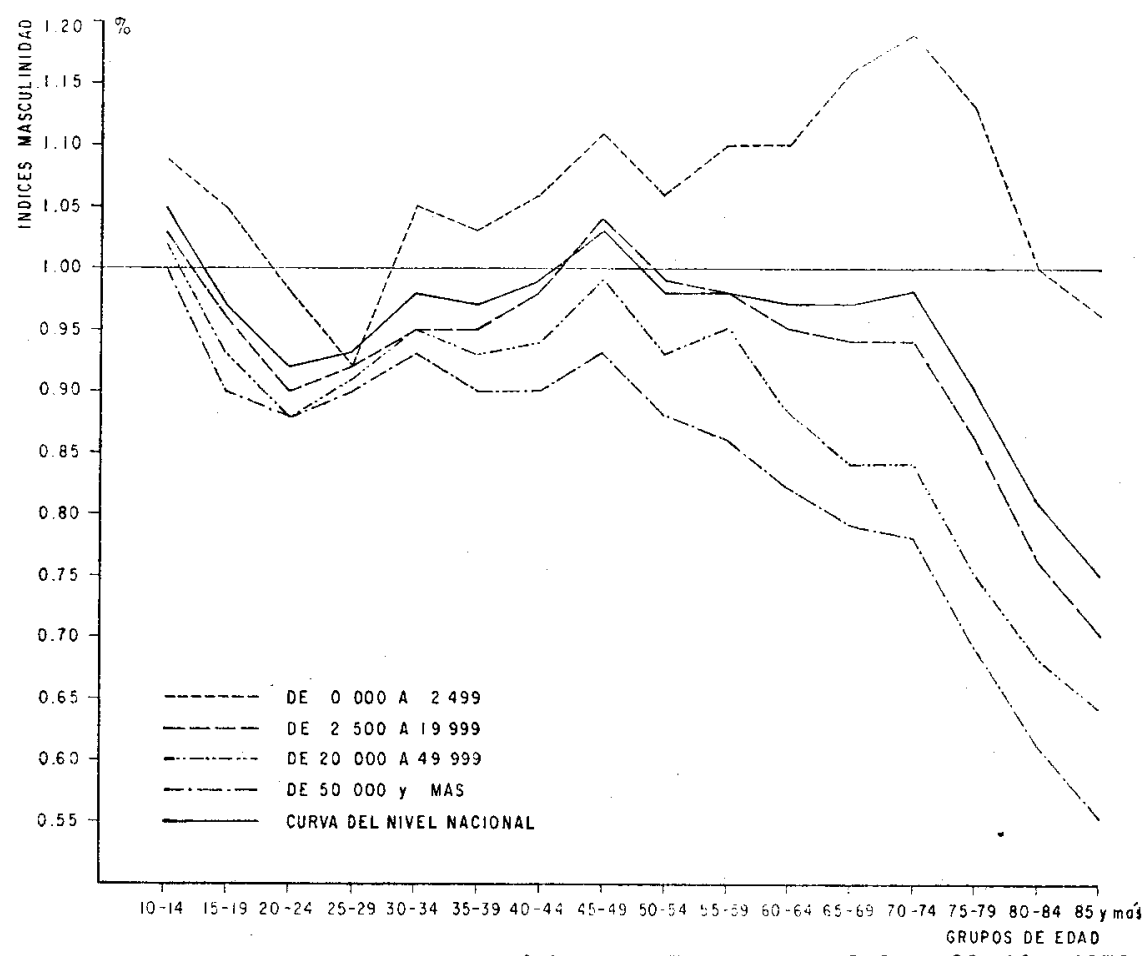

Funnte: Dirección General de Estadística, IX Censo General de Población, 1970. México, Secretaría de Industria y Comercio. 


\section{Cuadro 2.1}

MÉxico: INDICES DE MASCULINIDAD SEGÚN TAMAÑo DE LOCALIDAD, 1970

\begin{tabular}{|c|c|c|c|c|c|}
\hline \multirow[b]{2}{*}{ Grupos de edad } & \multicolumn{5}{|c|}{ Temaño de localidad } \\
\hline & $0-2499$ & $\begin{array}{l}2560 \mathrm{a} \\
19999\end{array}$ & $\begin{array}{lll}20 & 000 & a \\
49 & 999\end{array}$ & $\begin{array}{l}50000 \\
y \text { más }\end{array}$ & Total \\
\hline $10-10$ & 1.09 & 1.03 & 1.02 & 1.00 & 1.05 \\
\hline $15-19$ & 1.05 & 0.96 & 0.93 & 0.90 & 0.97 \\
\hline $20-24$ & 0.98 & 0.90 & 0.88 & 0.88 & 0.92 \\
\hline $25-29$ & 0.92 & 0.92 & 0.91 & 0.90 & 0.93 \\
\hline $30-34$ & 1.05 & 0.95 & 0.95 & 0.93 & 0.98 \\
\hline $35-39$ & 1.03 & 0.95 & 0.93 & 0.90 & 0.97 \\
\hline $40+44$ & 1.06 & 0.93 & 0.94 & 0.90 & 0.99 \\
\hline $45-49$ & 1.11 & 1.04 & 0.99 & 0.93 & 1.03 \\
\hline $50-54$ & 1.06 & 0.99 & 0.93 & 0.88 & 0.98 \\
\hline $55-59$ & 1.10 & 0.98 & 0.95 & 0.86 & 0.98 \\
\hline $60-64$ & 1.10 & 0.95 & $0.88^{\circ}$ & 0.82 & 0.97 \\
\hline $65-69$ & 1.17 & 0.94 & 0.84 & 0.79 & 0.97 \\
\hline $70-74$ & 1.19 & 0.94 & 0.84 & 0.78 & 0.98 \\
\hline $75-79$ & 1.13 & 0.86 & 0.75 & 0.69 & 0.90 \\
\hline $80-84$ & 1.00 & 0.76 & 0.68 & 0.61 & 0.81 \\
\hline $85 y$ más & 0.96 & 0.70 & 0.64 & $0.5 \tilde{5}$ & 0.75 \\
\hline Total & 1.05 & 0.98 & 0.93 & 0.90 & 0.98 \\
\hline
\end{tabular}

por objeto no atribuir las posibles diferencias que se encuentran a problemas derivados de la calidad de la información.

Los índices calculados dan cuenta de una menor proporción de mujeres que de hombres en las edades avanzadas, siendo la falta de mujeres tanto más acusada cuanto más rural es el tipo de localidad. Análisis ya efectuados sobre estos índices para el conjunto del país indican que entre los 12 y los 45 años de edad hay una mayor proporción de mujeres que de hombres cuando lo esperado en esas edades es un equilibrio entre los sexos. A partir de los 45 años, los índices en lugar de descender paulatinamente con la edad como efecto de la sobremortalidad masculina, se mantienen $\mathrm{e}$ incluso suben.

Los índices de masculinidad correspondientes al área rural son los que más se alejan del comportamiento que deberían seguir (véanse el cuadro 2.1 , y la gráfica 3 ). Adoptan valores por debajo de 100 (más mujeres que hombres) en las edades en que se celebran las uniones y donde normalmente prevalece un equilibrio entre ambos sexos; y, por encima de 100 (menos mujeres que hombres), en las edades que la sobremortalidad masculina, según sea su intensidad, los hace descender en forma más o menos rápida.

La explicación más plausible sería la de atribuir las diferencias entre indices por tamaños de localidad a dos problemas: a) subenumeración de 
mujeres especialmente acentuada en las áreas rurales y; $b$ ) declaración de una edad más joven que la que realmente tienen por parte de las mujeres, lo cual lleva a ubicarlas en grupos más jóvenes que al que verdaderamente pertenecen.

En relación con la nupcialidad, un faltante de hombres en las edades en que se celebran las uniones provoca un desequilibrio en los efectivos en presencia de cada sexo, que puede repercutir sobre la edad al contraer la unión como también sobre la proporción final de hombres y mujeres que lleguen a contraer al menos una unión.

\section{ANEXO 3}

Cuadro 3.1

Proporción acumulada de MUJeres unidas al MENos UNA Vez, SEGÚN LA EDAd A LA PRIMERA UNIÓN Y EDAD ACTUAL CON RESPECTO AL TOTAL DE MUJERES EN CADA GRUPO DE EDAD

(Porcientos)

\begin{tabular}{cccccccc}
\hline \multirow{2}{*}{$\begin{array}{c}\text { Edad } \\
\text { (primera unión) }\end{array}$} & \multicolumn{7}{c}{ Edad actual y generación } \\
\cline { 2 - 8 } & $\begin{array}{c}15-19 \\
1950-54\end{array}$ & $\begin{array}{c}20-24 \\
1945-49\end{array}$ & $\begin{array}{c}25-29 \\
1940-44\end{array}$ & $\begin{array}{c}30-34 \\
1935-39\end{array}$ & $\begin{array}{l}35-39 \\
1930-34\end{array}$ & $\begin{array}{l}40-44 \\
1925-29\end{array}$ & $\begin{array}{c}45-49 \\
1920-24\end{array}$ \\
\hline & & & & & & & \\
15 & 8.6 & 10.9 & 15.8 & 12.3 & 11.1 & 17.2 & 13.9 \\
20 & & $57-3$ & 65.3 & 67.0 & 60.2 & 64.8 & 60.3 \\
25 & & & 83.0 & 85.9 & 88.0 & 84.2 & 80.1 \\
30 & & & & 90.2 & 93.3 & 90.0 & 86.9 \\
35 & & & & & 94.3 & 91.6 & 89.4 \\
40 & & & & & & 92.6 & 90.7 \\
45 & & & & & & 91.1 \\
\hline
\end{tabular}

\section{Cuadro 3.2}

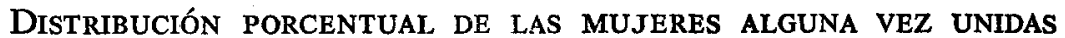
SEGÚN EDAD A LA PRIMERA UNIÓN Y NATURALEZA DE LA UNIÓN ÚLTIMA

\begin{tabular}{|c|c|c|c|c|c|c|c|}
\hline \multirow{2}{*}{$\begin{array}{l}\text { Naturaleza } \\
\text { unión altima }\end{array}$} & \multicolumn{6}{|c|}{ Edad a la primera unión } & \multirow{2}{*}{ Total } \\
\hline & -15 & $15-17$ & $18-19$ & $20-21$ & $22-24$ & 25 y mäs. & \\
\hline Natrimonio sôlo civil & 16.0 & 41.9 & 20.8 & 9.6 & 7.5 & 4.2 & 100 \\
\hline Matrinonio civil y religioso & 13.8 & 38.2 & 19.1 & 13.5 & 9.5 & 5.9 & 100 \\
\hline Convivencia & 26.2 & 43.0 & 14.1 & 7.0 & 5.7 & 4.9 & 100 \\
\hline
\end{tabular}


Cuadro 3.3

MUJERES ACTUALMENTE UNIDAS CON UNA SOLA UNIÓN SEGÚN GRUPOS DE EDADES Y NATURALEZA EN LA ÚLTIMA UNIÓN

$(\text { porcientos })^{\mathrm{a}}$

\begin{tabular}{|c|c|c|c|c|c|c|c|c|}
\hline & $15-19$ & $20-24$ & $25-29$ & $30-34$ & $35-39$ & $40-44$ & $45-49$ & Total \\
\hline $\begin{array}{l}\text { Matrimonio sólo } \\
\text { civill }\end{array}$ & $\begin{array}{l}17.0 \\
(47)\end{array}$ & $\begin{array}{l}19.9 \\
(55)\end{array}$ & $\begin{array}{l}21.1 \\
(61)\end{array}$ & $\begin{array}{l}76.6 \\
(43)\end{array}$ & $\begin{array}{l}12.0 \\
(33)\end{array}$ & $\begin{array}{r}9.4 \\
(26)\end{array}$ & $\begin{array}{l}4.0 \\
(11)\end{array}$ & $\begin{array}{l}100.0 \\
(176)\end{array}$ \\
\hline $\begin{array}{l}\text { Matrimonio civil } \\
\text { y religioso }\end{array}$ & $\begin{array}{l}6.8 \\
(73)\end{array}$ & $\begin{array}{l}14.1 \\
(15 i)\end{array}$ & $\begin{array}{l}21.1 \\
(226)\end{array}$ & $\begin{array}{l}17.2 \\
(184)\end{array}$ & $\begin{array}{l}18.1 \\
(19.3)\end{array}$ & $(134)$ & $\left(\begin{array}{l}10.1 \\
(108)\end{array}\right.$ & $\begin{array}{r}100.0 \\
(1069)\end{array}$ \\
\hline Convivientes & $\begin{array}{l}74.4 \\
(39)\end{array}$ & $\begin{array}{l}21.4 \\
(58)\end{array}$ & $\begin{array}{l}26.1 \\
(71)\end{array}$ & $\begin{array}{l}12.9 \\
(35)\end{array}$ & $\begin{array}{l}10.7 \\
(29)\end{array}$ & $\begin{array}{l}10.0 \\
(27)\end{array}$ & $\begin{array}{l}4.4 \\
(12)\end{array}$ & $\begin{array}{l}100.0 \\
(271)\end{array}$ \\
\hline Total & $\begin{array}{r}9.8 \\
(159)\end{array}$ & $\begin{array}{l}16.3 \\
(264)\end{array}$ & $\begin{array}{r}22.2 \\
(358)\end{array}$ & $\begin{array}{r}16.2 \\
(262)\end{array}$ & $\begin{array}{r}15.8 \\
(255)\end{array}$ & $\begin{array}{l}11.6 \\
(187)\end{array}$ & $\begin{array}{r}8.1 \\
(131)\end{array}$ & $\begin{array}{r}100.0 \\
(1616)\end{array}$ \\
\hline
\end{tabular}

a Las cifras entre paréntesis corresponden al número de casos.

Cuadro 3.4

MUJERES ACTUALMENTE UNIDAS CON UNA O MÁS UNIONES SEGÚN GRUPOS DE EDADES Y NATURALEZA DE LA UNIÓN ÚLTIMA (porcientos) ${ }^{\mathrm{a}}$

\begin{tabular}{|c|c|c|c|c|c|c|c|c|}
\hline & $15-19$ & $20-24$ & $25-29$ & $30-34$ & $35-39$ & $40-44$ & $45-49$ & Tota1 \\
\hline $\begin{array}{l}\text { Matrimonio sổo } \\
\text { civil }\end{array}$ & $\begin{array}{l}15.3 \\
(5 i)\end{array}$ & $\begin{array}{l}19.8 \\
(66)\end{array}$ & $\begin{array}{l}22.5 \\
(75)\end{array}$ & $\begin{array}{l}15.9 \\
(53)\end{array}$ & $\begin{array}{l}11.3 \\
(38)\end{array}$ & $\begin{array}{l}10.2 \\
(34)\end{array}$ & $\begin{array}{r}5.1 \\
(17)\end{array}$ & $\begin{array}{l}100.0 \\
(354)\end{array}$ \\
\hline $\begin{array}{l}\text { Natrimonio civil } \\
\text { y religioso }\end{array}$ & $\begin{array}{r}6.5 \\
(81)\end{array}$ & $\begin{array}{r}14.2 \\
(178)\end{array}$ & $\begin{array}{r}20.3 \\
(254)\end{array}$ & $\begin{array}{r}17.4 \\
(217)\end{array}$ & $\begin{array}{r}18.3 \\
(229)\end{array}$ & $\begin{array}{l}12.4 \\
(155)\end{array}$ & $\begin{array}{r}10.9 \\
(136)\end{array}$ & $\begin{array}{r}100.0 \\
(1250)\end{array}$ \\
\hline Convivencia & $\begin{array}{l}11.5 \\
(44)\end{array}$ & $\begin{array}{l}17.8 \\
(68)\end{array}$ & $\begin{array}{l}22.0 \\
(34)\end{array}$ & $\begin{array}{l}14.7 \\
(56)\end{array}$ & $\begin{array}{l}13.9 \\
(53)\end{array}$ & $\begin{array}{l}12.0 \\
(46)\end{array}$ & $\begin{array}{r}8.1 \\
(31)\end{array}$ & $\begin{array}{l}100.0 \\
(382)\end{array}$ \\
\hline Tota1 & $\begin{array}{r}8.9 \\
(176)\end{array}$ & $\begin{array}{r}15.9 \\
(312)\end{array}$ & $\begin{array}{c}21.0 \\
(413)\end{array}$ & $\begin{array}{c}16.6 \\
(326)\end{array}$ & $\begin{array}{c}16.3 \\
(320)\end{array}$ & $\begin{array}{r}12.0 \\
(235)\end{array}$ & $\begin{array}{r}9.4 \\
(184)\end{array}$ & $\begin{array}{r}100.0 \\
(1966)\end{array}$ \\
\hline
\end{tabular}

a Las cifras entre paréntesis corresponden al número de casos. 


\section{ANEXO 4}

ORDENAMIENTO DE LAS REGIONES SEGÚN LOS VALORES DE SUS INDICADORES SOCIALES Y ECONÓMICOS (LUGARES DEL 1 AL 9)

\begin{tabular}{|c|c|c|c|c|c|c|}
\hline & & \multicolumn{3}{|c|}{ Indicadores Sociales } & \multicolumn{2}{|c|}{$\begin{array}{c}\text { Indicadores Economicos } \\
\text { (PEA) }\end{array}$} \\
\hline & & N1fabetismo & $\begin{array}{l}\text { Vivienda } \\
\text { con drenaje }\end{array}$ & $\begin{array}{l}\text { Vivienda con } \\
\text { energía elec } \\
\text { trica }\end{array}$ & $\begin{array}{l}\text { En el sector } \\
\text { terciario }\end{array}$ & $\begin{array}{c}\text { Con ingresos } \\
\geqslant 1500 \\
\text { mensuales }\end{array}$ \\
\hline \multicolumn{7}{|c|}{ Grujo A } \\
\hline VII & $\begin{array}{l}\text { Centro Sur } \\
\frac{0}{6} \\
\text { Lugar }\end{array}$ & $\frac{84.0}{3}$ & 61.0 & 80.0 & 48.5 & 23.8 \\
\hline I & $\begin{array}{l}\text { Noroeste } \\
\text { Lugar }\end{array}$ & $\begin{array}{c}85.2 \\
2\end{array}$ & 39.6 & $\frac{64.6}{2}$ & $\begin{array}{c}38.8 \\
2\end{array}$ & 20.3 \\
\hline II & $\begin{array}{l}\text { Noreste } \\
\vdots \\
\text { Lugar }\end{array}$ & $\begin{array}{c}85.7 \\
1\end{array}$ & $\begin{array}{c}42.2 \\
3\end{array}$ & $\begin{array}{c}61.2 \\
4\end{array}$ & $\begin{array}{c}35.3 \\
3\end{array}$ & $\begin{array}{c}16.6 \\
3\end{array}$ \\
\hline IV & $\begin{array}{l}\text { Centro } \\
\text { Occidertal } \\
\frac{0}{3} \\
\text { Jugar }\end{array}$ & $\begin{array}{c}81.1 \\
4\end{array}$ & $\begin{array}{c}49.0 \\
2\end{array}$ & $\frac{64.5}{3}$ & $\begin{array}{c}34.6 \\
4\end{array}$ & $\begin{array}{c}12.7 \\
5\end{array}$ \\
\hline \multicolumn{7}{|c|}{ Grupo 3} \\
\hline VIII & $\begin{array}{l}\text { Golfo de Mexico } \\
\text { of } \\
\text { Lugar }\end{array}$ & $\begin{array}{c}71.1 \\
5\end{array}$ & $\begin{array}{c}58.7 \\
5\end{array}$ & $\begin{array}{c}54.1 \\
5\end{array}$ & $\begin{array}{c}28.9 \\
5\end{array}$ & $\begin{array}{c}13.1 \\
4\end{array}$ \\
\hline $\mathrm{V}$ & $\begin{array}{l}\text { Centro } \\
\text { Lugar } \\
\text { Lugar }\end{array}$ & $\begin{array}{c}67.4 \\
7\end{array}$ & $\begin{array}{c}35.8 \\
6\end{array}$ & $\begin{array}{c}52.1 \\
6\end{array}$ & 24.5 & $\underset{6}{8.5}$ \\
\hline Grupo & & & & & & \\
\hline III & $\begin{array}{l}\text { Pacifico Sur } \\
\frac{0}{6} \\
\text { Lugar }\end{array}$ & $\underset{9}{59.5}$ & $\begin{array}{c}24.6 \\
7\end{array}$ & $\begin{array}{c}39.0 \\
7\end{array}$ & 21.6 & $\begin{array}{c}7.4 \\
7\end{array}$ \\
\hline VI & $\begin{array}{l}\text { Centro Golfo } \\
\frac{a}{6} \\
\text { Lugar }\end{array}$ & $\begin{array}{c}67.8 \\
6\end{array}$ & 23.7 & 37.3 & $\stackrel{18.6}{8}$ & $\begin{array}{c}7.2 \\
8\end{array}$ \\
\hline IX & $\begin{array}{l}\text { Golfo-Península } \\
\text { de Yucatán } \\
: \\
\text { lugar }\end{array}$ & $\frac{63.3}{8}$ & 21.3 & 34.2 & ${ }_{9}^{17.8}$ & $\begin{array}{c}5.7 \\
9\end{array}$ \\
\hline
\end{tabular}

Fuente: C. Welti, "Regionalización en la Encuesta de Fecundidad Rural", Mimeo., Cuadro 1. 
ANEXO 5

INDICE DE MASCULINIDAD POR REGIONES ${ }^{a}$

\begin{tabular}{|c|c|c|c|c|c|c|c|c|c|}
\hline \multirow{2}{*}{$\begin{array}{l}\text { Grupos } \\
\text { de edad }\end{array}$} & \multicolumn{9}{|c|}{ Regiones } \\
\hline & $I$ & II & III & IV & $\mathrm{V}$ & VI & VII & VIII & $I X$ \\
\hline \multicolumn{10}{|c|}{ Región en su conjunto } \\
\hline $15-19$ & 1.02 & 0.99 & 1.00 & 0.97 & 1.00 & 1.04 & 0.93 & 0.99 & 0.96 \\
\hline $20-24$ & 0.93 & 0.93 & 0.89 & 0.91 & 0.93 & 0.94 & 0.92 & 0.92 & 0.90 \\
\hline $25-29$ & 0.36 & 0.95 & 0.90 & 0.92 & 0.94 & 0.94 & 0.94 & 0.94 & 0.90 \\
\hline \multicolumn{10}{|c|}{ Localidades de menos de 20000} \\
\hline \multicolumn{10}{|c|}{ habitantes } \\
\hline $15-19$ & 1.05 & 1.05 & 1.02 & 1.01 & 1.02 & 1.07 & 0.98 & 1.03 & 0.98 \\
\hline $20-24$ & 1.02 & 0.98 & 0.91 & 0.93 & 0.97 & 0.96 & 0.93 & 0.96 & 0.92 \\
\hline $25-29$ & 1.04 & 0.98 & 0.91 & 0.93 & 0.94 & 0.95 & 0.95 & 0.97 & 0.92 \\
\hline
\end{tabular}

Fuente: Dirección General de Estadística, IX Censo General de Población, 1970, cuadro 5, México, Secretaría de Industria y Comercio.

a Se trata de una reagrupación de entidades que se aproxima a la de las regiones definidas en la encuesta. 